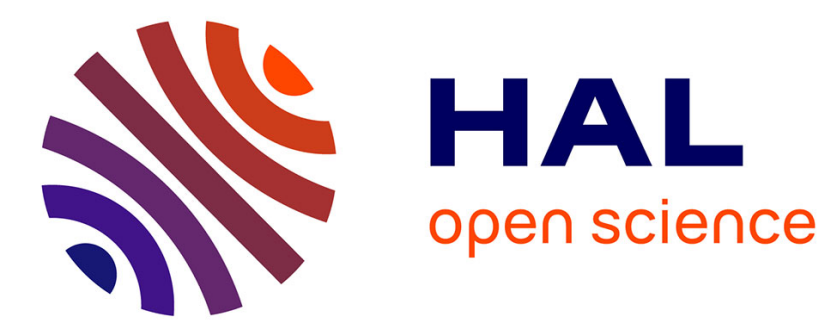

\title{
On the statistical identification of DSGE models
}

Agostino Consolo, Carlo A. Favero, Alessia Paccagnini

\section{To cite this version:}

Agostino Consolo, Carlo A. Favero, Alessia Paccagnini. On the statistical identification of DSGE models. Econometrics, 2009, 150 (1), pp.99. 10.1016/j.jeconom.2009.02.012 . hal-00578278

\section{HAL Id: hal-00578278 \\ https://hal.science/hal-00578278}

Submitted on 19 Mar 2011

HAL is a multi-disciplinary open access archive for the deposit and dissemination of scientific research documents, whether they are published or not. The documents may come from teaching and research institutions in France or abroad, or from public or private research centers.
L'archive ouverte pluridisciplinaire HAL, est destinée au dépôt et à la diffusion de documents scientifiques de niveau recherche, publiés ou non, émanant des établissements d'enseignement et de recherche français ou étrangers, des laboratoires publics ou privés. 


\section{Accepted Manuscript}

On the statistical identification of DSGE models

Agostino Consolo, Carlo A. Favero, Alessia Paccagnini

PII:

S0304-4076(09)00048-7

DOI:

10.1016/j.jeconom.2009.02.012

Reference: $\quad$ ECONOM 3169

To appear in: Journal of Econometrics

Received date: 28 June 2007

Revised date: 15 January 2009

Accepted date: 3 February 2009

Please cite this article as: Consolo, A., Favero, C.A., Paccagnini, A., On the statistical identification of DSGE models. Journal of Econometrics (2009), doi:10.1016/j.jeconom.2009.02.012

This is a PDF file of an unedited manuscript that has been accepted for publication. As a service to our customers we are providing this early version of the manuscript. The manuscript will undergo copyediting, typesetting, and review of the resulting proof before it is published in its final form. Please note that during the production process errors may be discovered which could affect the content, and all legal disclaimers that apply to the journal pertain. 


\title{
On the Statistical Identification of DSGE models*
}

\author{
Agostino Consolo, Carlo A. Favero, Alessia Paccagnini ${ }^{\dagger}$ \\ January 15, 2009
}

\begin{abstract}
Dynamic Stochastic General Equilibrium (DSGE) models are now considered attractive by the profession not only from the theoretical perspective but also from an empirical standpoint. As a consequence of this development, methods for diagnosing the fit of these models are being proposed and implemented. In this article we illustrate how the concept of statistical identification, that was introduced and used by Spanos(1990) to criticize traditional evaluation methods of Cowles Commission models, could be relevant for DSGE models. We conclude that the recently proposed model evaluation method, based on the $D S G E-V A R(\lambda)$, might not satisfy the condition for statistical identification. However, our application also shows that the adoption of a FAVAR as a statistically identified benchmark leaves unaltered the support of the data for the DSGE model and that a DSGE-FAVAR can be an optimal forecasting model.

Keywords: Bayesian analysis; Dynamic stochastic general equilibrium model; Model evaluation,Statistical Identification,Vector autoregression, Factor-Augmented Vector Autoregression.
\end{abstract}

JEL Classification: C11, C52

\section{Introduction}

Dynamic Stochastic General Equilibrium (DSGE) models are now considered attractive by the profession not only from the theoretical perspective but also for empirical analysis and for econometric policy simulation. ${ }^{1}$ Model evaluation

*We thank Marco Del Negro for having kindly provided us with the Matlab programs used in Del Negro-Schorfheide(2004). We are also grateful to participants in the Applied Macroeconometric Network for useful comments. Carlo Favero is especially grateful to Katarina Juselius for her strong encouragement to write this paper. All errors are our own.

${ }^{\dagger}$ Consolo: IGIER(Università Bocconi). Favero: IGIER (Universita' Bocconi), AMeN and Dept of Finance (Universita' Bocconi) and CEPR. Paccagnini, IGIER (Università Bocconi).

${ }^{1}$ See An and Schorfheide(2006) and the JBES Invited address presented at the Joint Statistical Meeting 2006 "On the Fit of New Keynesian Models" by Del Negro, Schorfheide, Smets and Wouters, published on the April 2007 issue of the JBES with comments by L.Christiano, R.Gallant, C.Sims, J.Faust, and L.Killian. 
is an issue of crucial importance before policy simulation. Therefore, methods for diagnosing the fit of these models are being proposed and implemented. This article illustrates how the concept of statistical identification, originally introduced to criticize traditional evaluation methods of Cowles Commission models, could also be applied to the diagnostic tools recently proposed for DSGE models.

The concept of statistical identification has been introduced by Spanos(1990). Structural models can be viewed statistically as a reparameterization, possibly (in case of over-identified models) with restrictions, of the reduced form. Spanos distinguishes between structural identification and statistical identification. Structural identification refers to the uniqueness of the structural parameters, as defined by the reparameterization and restriction mapping from the statistical parameters in the reduced form, while statistical identification refers to the choice of a well-defined statistical model as reduced form. Diagnostics for model evaluation are constructed in Cowles commission tradition in a way that is closely related to the solution of the identification problem. In fact, in the (very common) case of over-identified models, a test of the validity of the over-identifying restrictions can be constructed by comparing the restricted reduced form implied by the structural model with the reduced form implied by the just-identified model in which each endogenous variables depend on all exogenous variables with unrestricted coefficients. The statistics are derived in Anderson and Rubin(1949) and Basman(1960). The logic of the test attributes a central role to the structural model. The statistical model of reference for the evaluation of the structural model is derived by the structural model itself. Spanos(1990) points out that the root of the failure of the Cowles Commission approach lies in the little attention paid to the statistical model implicit in the estimated structure. Any identified structure that is estimated without checking that the implied statistical model is an accurate description of the data is bound to fail if the statistical model is not valid. The Spanos critique of the Cowles commission approach lies naturally within the LSE approach to econometric modelling. Such approach reverses the prominence of the structural model with respect to the reduced form representation. The LSE approach starts its specification and identification procedure with a general dynamic reduced form model. The congruency of such a model cannot be directly assessed against the true DGP, which is unobservable. However, model evaluation is made possible by applying the general principle that congruent models should feature true random residuals; hence, any departure of the vector of residuals from a random normal multivariate distribution should signal a mis-specification. A structural model can be identified and estimated only after a validation procedure based on a battery of tests on the reduced form residuals has been satisfactorily implemented. A just-identified specification does not require any further testing, as its implied reduced form does not impose any further restrictions on the baseline statistical model. The validity of over-identified specification is instead tested by evaluating the validity of the restrictions implicitly imposed on the general reduced form. Interestingly, the lack of statistical identification offers an explanation for the failure of the Cowles Commission models very different 
from the "great critiques" by Lucas(1976) and Sims(1980), that concentrate on model failure related to structural identification problems.

The structural identification problem for DSGE has recently received some close attention (Canova and Sala(2006)). This paper concentrates on the statistical identification model of DSGE models. We illustrate how the logic of some recently proposed model evaluation tools for DSGE models, based on the comparative evaluation of a DSGE-VAR model with an unrestricted VAR model, resembles closely the logic applied within the Cowles Commission approach in testing for the validity of over-identifying restrictions in structural models. We then show that statistical identification can be achieved by using a Factor Augmented VAR (FAVAR), and we compare the properties of DSGE-VAR and DSGE-FAVAR. We provide an empirical illustration by considering the case of a very simple three-equations DSGE model (Del Negro and Schorfheide(2004)).

\section{Statistical Identification: the original concept}

Spanos (1990) considers the case of a simple demand and supply model to show how the reduced form is ignored in the traditional approach. The example is based on the market for commercial loans discussed in Maddala (1988). Most of the widely used estimators allow the derivation of numerical values for the structural parameters without even seeing the statistical models represented by the reduced form. Following this tradition, the estimated (by 2SLS) structural model is a static model that relates the demand for loans to the average prime rate, to the Aaa corporate bond rate and to the industrial production index, while the supply of loans depends on the average prime rate, the three-month bill rate and total bank deposits. The quantity of commercial loans and the average prime rate are considered as endogenous while all other variables are taken as, at least, weakly exogenous variables in the sense of Engle et al. (1983) and no equation for them is explicitly estimated. Given that there are two omitted instruments in each equation, one over-identifying restriction is imposed in both the demand and supply equations. The validity of the restrictions is tested via the Anderson-Rubin (1949) tests, and leads to the rejection of the restrictions at the 5 per cent level in both equations, although in the second equation the restrictions cannot be rejected at the 1 per cent level. This mild evidence against the adopted structural model ignores the fact that estimation of the statistical model, i.e. the reduced form implied by the adopted identifying restrictions, yields a specification for which the underlying statistical assumptions of linearity, homoscedasticity, absence of autocorrelation and normality of residuals are all strongly rejected. On the basis of this evidence the adopted statistical model is not considered as appropriate. An alternative model allowing for a richer dynamic structure (two lags) in the reduced form is then considered. Such dynamic specification is shown to provide a much better statistical model for the data than the static reduced from. Of course, the adopted structural model implies many more over-identifying restrictions than the initial more parsimonious specification. When tested, the validity of these restrictions is overwhelmingly 
rejected for both the demand and the supply equations. Such evidence leads to the conclusion that the lack of statistical identification of the original model might lead to failure of rejecting the structural model of interest when it is false.

In practice, Cowles Commission models have been abandoned because of their empirical failure and because of the great critiques related to their lack of structural identification, much less emphasis has been posed by the mainstream literature on the problem of statistical identification, with the notable exception of the LSE approach to econometric dynamics (see, Hendry,1995). Cowles Commission models for policy evaluation have been replaced by Dynamic Stochastic General Equilibrium (DSGE) models.

\section{The Statistical Identification of VAR and DSGE models}

The general linear (or linearized around equilibrium) DSGE model takes the following form(see Sims(2002)):

$$
\boldsymbol{\Gamma}_{0} \mathbf{Z}_{t}=\boldsymbol{\Gamma}_{1} \mathbf{Z}_{t-1}+C+\Psi \epsilon_{t}+\Pi \eta_{t}
$$

Where $C$ is a vector of constants, $\epsilon_{t}$ is an exogenously evolving random disturbance, $\eta_{t}$ is a vector of expectations errors, $\left(E_{t}\left(\eta_{t+1}\right)=\mathbf{0}\right)$, not given exogenously but to be treated as part of the model solution. The forcing processes here are the elements of the vector $\epsilon_{t}$, this typically contains processes like Total Factor Productivity or policy variables that are not determined by an optimization process. Policy variables set by optimization, typically included $\mathbf{Z}_{t}$, are naturally endogenous as optimal policy requires some response to current and expected developments of the economy. Expectations at time $t$ for some of the variables of the systems at time $t+1$ are also included in the vector $\mathbf{Z}_{t}$, whenever the model is forward looking. Model like (1)can be solved using standard numerical techniques (see, for example, Sims, 2002), and the solution can be expressed as:

$$
\mathbf{Z}_{t}=\mathbf{A}_{0}+\mathbf{A}_{1} \mathbf{Z}_{\mathbf{t}-\mathbf{1}}+\mathbf{R} \epsilon_{t}
$$

where the matrices $\mathbf{A}_{0}, \mathbf{A}_{1}$, and $\mathbf{R}$ contain convolutions of the underlying model structural parameters. Consider the simple case in which all variables in the DSGE are observable and the number of structural shocks in $\epsilon_{t}$ is exactly equal to the number of variables in $\mathbf{Z}_{t}$. In this case VAR are natural specifications for the data, therefore the estimated reduced form in modern macroeconometrics is:

$$
\mathbf{Z}_{t}=\mathbf{A}_{0}+\mathbf{A}_{1} \mathbf{Z}_{\mathbf{t}-\mathbf{1}}+\mathbf{u}_{t}
$$

Within this framework a new role for empirical analysis based on reduced form models emerges, that is to provide evidence on the stylized facts to be matched by the theoretical model adopted for policy analysis and to decide 
between competing DSGE models. Given the estimation of a VAR the selection of a particular DSGE model among different alternatives can be based on the following three steps (see Christiano, Eichenbaum and Evans (1998)):

1. policy shocks of interests are identified in actual economies, i.e. in a VAR without theoretical restrictions;

2. the response of relevant economic variables to these shocks is then described;

3. finally, the same experiment is performed in the model economies (DSGE) to compare actual and model-based responses as an evaluation tool and a selection criterion for theoretical models.

The identification of the shocks of interest is the structural identification problem in VAR-based model evaluation. VAR modelling recognizes that identification and estimation of structural parameters is impossible without explicitly modelling expectations, therefore a structure like (3) can only be used to run special experiments that do not involve simulating different scenarios for the parameters of interests. A natural way to achieve these results is to experiment with the shocks $\epsilon_{t}$. Facts are then provided by looking at impulse response analysis, variance decompositions and historical decompositions. All these experiments are run by keeping estimated parameters unaltered. Importantly, running these experiments is easier if shocks to the different variables included in the VAR are orthogonal to each other, otherwise it would not be possible to simulate a policy shock by maintaining all the other shocks at zero. As a consequence, VAR models need a structure because orthogonal shocks are normally not a feature of the statistical model. This fact generates the structural identification problem. The relation between (3) and (2)implies that:

$$
\mathbf{u}_{t}=\mathbf{R} \epsilon_{t},
$$

from which we can derive the relation between the variance-covariance matrices of $\mathbf{u}_{t}$ (observed) and $\boldsymbol{\nu}_{t}$ (unobserved) as follows:

$$
E\left(\mathbf{u}_{t} \mathbf{u}_{t}^{\prime}\right)=\mathbf{R} E\left(\epsilon_{t} \epsilon_{t}{ }^{\prime}\right) \mathbf{R}^{\prime} .
$$

Substituting population moments with sample moments the relevant structural shocks can be identified and a number of parameters in the $\mathbf{R}$ matrix equal up to the number of different elements in the variance covariance matrix of the VAR innovations $(m(m+1) / 2$, where $m$ is the number of variables included in the VAR ) can be estimated. As usual, for such a condition also to be sufficient for identification, no equation in (4) should be a linear combination of the other equations in the system (see Amisano and Giannini 1996, Hamilton 1994). As for traditional models, we have the three possible cases of under-identification, just-identification and over-identification. The validity of over-identifying restrictions can be tested via a statistic distributed as a $\chi^{2}$ with the number of degrees of freedom equal to the number of over-identifying 
restrictions. But again structural identification of a VAR is a totally different from statistical identification. In fact, misspecification of a VAR generated by omitted variables does not prevent structural identification but it leads to lack of statistical identification. ${ }^{2}$

Recent Model Evaluation of DSGE models exploits the fact that a solved RBC model is a statistical model. In fact, solved DSGE model often generates a restricted MA representation for the vector of observable variables of interest, that can be approximated by a VAR of finite order (see Fernandez-Villaverde et al.(2007) and Ravenna, (2007)). Interestingly, this recent approach to model evaluation does not require identification of structural shocks but it is still potentially affected by lack of statistical identification.

To see this point consider the general case of system (2) in which only a subset $n$ of the $m$ variables included in $\mathbf{Z}_{t}$ is observable and define such subset $\mathbf{Y}_{t} . \mathbf{Y}_{t}$ has a $\operatorname{VAR}(\infty)$ representation. This is usually approximated by a finite VAR representation at the cost of a truncation that can be relevant for purposes such as the identification of structural shocks (see Ravenna(2007)). Note that if the RBC model features a number of shocks smaller than the number of variables included in the VAR, some of the VAR shocks are interpreted as measurement error.

The finite approximate VAR representation of a solved $\mathrm{RBC}$ model is then written as the following structural VAR in which the number of shocks is equal to the length of the vector of observable variables $\mathbf{Y}_{t}$ :

$$
\begin{aligned}
& \mathbf{Y}_{t}=\boldsymbol{\Phi}_{0}^{*}(\theta)+\boldsymbol{\Phi}_{1}^{*}(\theta) \mathbf{Y}_{t-1}+\ldots+\boldsymbol{\Phi}_{p}^{*}(\theta) \mathbf{Y}_{t-p}+\mathbf{u}_{t}^{*} \\
& \mathbf{u}_{t}^{*} \sim N\left(\mathbf{0}, \Sigma_{u}^{*}(\theta)\right) \\
& \mathbf{Y}=\mathbf{X} \boldsymbol{\Phi}^{*}(\theta)+\mathbf{u}^{*} \\
& \underset{T x n}{\mathbf{u}^{*}}=\left[\begin{array}{ccc}
\mathbf{u}_{1}^{*} & \cdots & \mathbf{u}_{n}^{*} \\
T x 1 & & T x 1
\end{array}\right] \\
& \underset{T x n}{\mathbf{Y}}=\left[\begin{array}{ccc}
\mathbf{Y}_{1} & \ldots & \mathbf{Y}_{n} \\
T x 1 & \cdots & T x 1
\end{array}\right] \\
& \underset{T x(n p+1)}{\mathbf{X}}=\left[\begin{array}{c}
\mathbf{X}_{1}^{\prime} \\
\mathbf{X}_{T}^{\prime}
\end{array}\right] \text {, } \\
& \underset{1 x(n p+1)}{\mathbf{X}_{t}^{\prime}}=\left[\begin{array}{cc}
1, \mathbf{Y}_{t-1}^{\prime} \cdots \mathbf{Y}_{t-p}^{\prime} \\
1 x n & 1 x n
\end{array}\right] \\
& \underset{(n p+1) x n}{\boldsymbol{\Phi}^{*}(\theta)}=\left[\underset{n x 1}{\boldsymbol{\Phi}_{0}^{*}(\theta)} \underset{n x n}{\boldsymbol{\Phi}_{1}^{*}(\theta)}, \ldots, \underset{n x n}{\boldsymbol{\Phi}_{p}^{*}(\theta)}\right]^{\prime},
\end{aligned}
$$

where all coefficients are convolutions of the structural parameters in the model included in the vector $\theta$. Of course the theoretical model imposes some

\footnotetext{
${ }^{2}$ Think for example of a simple Data Generating Process made of a bivariate cointegrated VAR with two strucutral shocks: a temporary one and a permanent one. The estimation of a VAR in difference omitting the cointegrating relations would not prevent structural identification of the two shocks but it would certainly lead to lack of statistical identification.
} 
restrictions on the VAR, that can be tested by evaluating them against the unrestricted VAR. Note that the relevant statistical model is constructed exactly as in the Cowles Commission approach: the specification of the statistical model is totally driven by that of the structural model. In fact, the statistical model is obtained by solving the structural model and then by relaxing some restrictions. As a matter of fact when this procedure is followed variables omitted from the structural model are never included in the statistical model and statistical identification becomes a potentially relevant issue. In a series of papers Del Negro and Schorfheide (2004, and 2006) and Del Negro, Schorfheide, Smets and Wouters(2004) adopt this line of research to propose a Bayesian framework for model evaluation. This method tilts coefficient estimates of an unrestricted VAR toward the restriction implied by a DSGE model. The weight placed on the DSGE model is controlled by an hyperparameter called $\lambda$. This parameter takes values ranging from 0 (no-weight on the DSGE model) to $\infty$ (no weight on the unrestricted VAR). Therefore, the posterior distribution of $\lambda$ provides an overall assessment of the validity of the DSGE model restrictions.

The chosen benchmark to evaluate this model is the unrestricted VAR derived from the solved DSGE model

$$
\begin{aligned}
\mathbf{Y}_{t} & =\boldsymbol{\Phi}_{0}+\mathbf{\Phi}_{1} \mathbf{Y}_{t-1}+\ldots+\mathbf{\Phi}_{p} \mathbf{Y}_{t-p}+\mathbf{u}_{t} \\
\mathbf{u}_{t} & \sim N\left(\mathbf{0}, \Sigma_{u}\right) \\
\mathbf{Y} & =\mathbf{X} \mathbf{\Phi}+\mathbf{u} \\
\underset{(n p+1) x n}{\mathbf{\Phi}} & =\left[\begin{array}{l}
\mathbf{\Phi}_{n x 1}, \mathbf{\Phi}_{1}, \ldots, \\
\mathbf{\Phi}_{p}
\end{array}\right]_{n x n}^{\prime}
\end{aligned}
$$

where:

$$
\begin{aligned}
\boldsymbol{\Phi} & =\boldsymbol{\Phi}^{*}(\theta)+\boldsymbol{\Phi}^{\Delta} \\
\Sigma_{u} & =\Sigma_{u}^{*}(\theta)+\Sigma_{u}^{\Delta}
\end{aligned}
$$

the DSGE restrictions are imposed on the VAR by defining:

$$
\begin{aligned}
\Gamma_{X X}(\theta) & =E_{\theta}^{D}\left[\mathbf{X}_{t} \mathbf{X}_{t}^{\prime}\right] \\
\Gamma_{X Z}(\theta) & =E_{\theta}^{D}\left[\mathbf{X}_{t} \mathbf{Y}_{t}^{\prime}\right]
\end{aligned}
$$

where $E_{\theta}^{D}$ defines the expectation with respect to the distribution generated by the DSGE model, that of course have to be well defined. We then have:

$$
\mathbf{\Phi}^{*}(\theta)=\Gamma_{X X}(\theta)^{-1} \Gamma_{X Y}(\theta)
$$

Beliefs about the DSGE model parameters $\theta$ and model misspecification matrices $\boldsymbol{\Phi}^{\Delta}$ and $\Sigma_{u}^{\Delta}$ are summarized in prior distributions, that, as shown in Del Negro and Schorfheide(2004) can be transformed into prior for the VAR parameters $\boldsymbol{\Phi}$ and $\Sigma_{u}$.In particular we have: 


$$
\begin{aligned}
\Sigma_{u} \mid \theta & \sim I W\left(\lambda T \Sigma_{u}^{*}(\theta), \lambda T-k, n\right) \\
\mathbf{\Phi} \mid \Sigma_{u}, \theta & \sim N\left(\boldsymbol{\Phi}^{*}(\theta), \frac{1}{\lambda T}\left[\Sigma_{u}^{-1} \otimes \Gamma_{X X}(\theta)\right]^{-1}\right)
\end{aligned}
$$

where the parameter $\lambda$ controls the degree of model misspecification with respect to the VAR: for small values of $\lambda$ the discrepancy between the VAR and the DSGE-VAR is large and a sizeable distance is generated between unrestricted VAR and DSGE estimators, large values of $\lambda$ correspond to small model misspecification and for $\lambda=\infty$ beliefs about DSGE mis-specification degenerate to a point mass at zero. Bayesian estimation could be interpreted as estimation based a sample in which data are augmented by an hypothetical sample in which observations are generated by the DSGE model, within this framework $\lambda$ determines the length of the hypothetical sample.

Given the prior distribution, posterior are derived by the Bayes theorem:

$$
\begin{aligned}
\Sigma_{u} \mid \theta, Y & \sim I W\left((\lambda+1) T \hat{\Sigma}_{u, b}(\theta),(\lambda+1) T-k, n\right) \\
\mathbf{\Phi} \mid \Sigma_{u}, \theta, Y & \sim N\left(\hat{\mathbf{\Phi}}_{b}(\theta), \Sigma_{u} \otimes\left[\lambda T \Gamma_{X X}(\theta)+\mathbf{X}^{\prime} \mathbf{X}\right]^{-1}\right) \\
\hat{\mathbf{\Phi}}_{b}(\theta) & =\left(\lambda T \Gamma_{X X}(\theta)+\mathbf{X}^{\prime} \mathbf{X}\right)^{-1}\left(\lambda T \Gamma_{X Y}(\theta)+\mathbf{X}^{\prime} \mathbf{Y}\right) \\
\hat{\Sigma}_{u, b}(\theta) & =\frac{1}{(\lambda+1) T}\left[\left(\lambda T \Gamma_{Y Y}(\theta)+\mathbf{Y}^{\prime} \mathbf{Y}\right)-\left(\lambda T \Gamma_{X Y}(\theta)+\mathbf{X}^{\prime} \mathbf{Y}\right) \hat{\mathbf{\Phi}}_{b}(\theta)\right]
\end{aligned}
$$

which shows that the smaller $\lambda$, the closer the estimates are to the OLS estimates of an unrestricted VAR, the higher $\lambda$ the closer the estimates are to the values implied by the DSGE model parameters $\theta$.

In practice, a grid search is conducted on a range of values for $\lambda$ to choose that value that maximize the marginal data density. The typical results obtained when using DSGE- $\operatorname{VAR}(\lambda)$ to evaluate models with frictions is that " ... the degree of misspecification in large-scale DSGE models is no longer so large as to prevent their use in day-to-day policy analysis, yet is not small enough that it cannot be ignored...".

DSGE-VAR model evaluation ignores the issue of specification of the statistical model. Although the models are different, the evaluation strategy in the DSGE-VAR approach is very similar to the approach of evaluating models by testing over-identifying restrictions without assessing the statistical model implemented in Cowles foundation models. In the Cowles Commission approach the statistical model was derived by taking the reduced form obtained by removing all the over-identifying restrictions implied by the theoretical model. As a consequence, as in the case of the market for loans analyzed by Spanos(1991), a static theoretical model would always be evaluated against a static statistical model, which would certainly lack statistical identification whenever the true 
Data Generating Process featured any form of dynamics. In the DSGE-VAR approach the fact that the a DSGE model is a restricted VAR is used to derive the statistical model by removing the DSGE restrictions from the VAR. However, the question of the validity of this unrestricted VAR to represent the data is not addressed. In fact, the DSGE-VAR approach is looser than the Cowles foundation approach: model based restrictions are not imposed and tested but are made fuzzy by imposing a distribution on them and then the relevant question becomes what is the amount of uncertainty that we have to add to model based restrictions in order to make them compatible with a model-derived unrestricted VAR representation of the data. In fact such representation might not represent the data. The natural question here is how well does this procedure do in rejecting false models? Spanos(1991) has shown clearly that generalizing the statistical model by adding features that are not included in the theoretical model (the omitted dynamics in the case of the static demand and supply for loans model considered in the original illustrative example) could lead to dramatic changes in the outcome of tests for over-identifying restrictions. Is the Spanos criticisms of Cowles Commission model evaluation applicable to DSGEVAR model evaluation?

\section{The statistical identification of a DSGE-FAVAR}

A DSGE model is a restricted VAR, removing the restrictions from the VAR and using an unrestricted VAR as a statistical model would imply that the Spanos criticism of the Cowles Commission model evaluation approach is applicable to DSGE-VAR model evaluation if the unrestricted VAR cannot be considered statistically identified. If the unrestricted VAR is not statistically identified we might not be able to conduct a proper statistical evaluation of the theoretical model by using it as a benchmark. The important point made by Spanos in his contribution is that reduced form of theoretical must be evaluated against specifications that captures the relevant information in the data potentially omitted from the theoretical model. Obviously the omission of dynamics used by Spanos to criticize the statistical identification of static Cowles Commission models is not applicable to VAR specifications. However, there are a number of potential sources of mis-specification for the model derived VAR. Think of all those variables that are omitted from the theoretical model because of its specific nature, say fiscal policy in a model designed to analyze the effect of monetary policy or foreign variables and the exchange rate in a closed economy model, but also of all variables that are not theory related but are relevant to determine the actual behaviour of policy makers. A good example is the commodity price index and the problem of modelling of the behaviour of monetary policy authority. Early VARs for the analysis of monetary policy that did not include in the information set a commodity price index tended to deliver a "price puzzle", i.e. a positive response of prices to an unexpected monetary tightening. Such anomaly has been attributed to the existence of a leading indicator for inflation to which the Fed reacts and which is omitted from the VAR. The omission form 
the information set of a variable positively correlated with inflation and interest rates makes the VAR mis-specified and explains the positive relation between prices and interest rates observed in the impulse response functions. It has been observed (see Christiano, Eichenbaum and Evans (1996)) that the inclusion of a Commodity Price Index in the VAR solves the 'price puzzle'. DSGE model do not typically include the commodity price index in their specification as a consequence the VAR derived by relaxing the theoretical restrictions in a DSGE model is misspecified. So the evaluation of the effects of conducting model misspecification with a "wrong" benchmark is a practically relevant one.

As a matter of fact DSGE model tend to produce a high number of very persistent shocks (see Smets and Wouters, 2003), such evidence would have been certainly taken as a signal of model mis-specification by an LSE type methodology. Still the model do not do too badly when judged in the metric of the $\lambda$ test.

Another dimension potentially relevant for evaluating the statistical model underlying DSGE-VAR is structural stability of the VAR parameters. If the DSGE restrictions are valid, then parameters in the VAR are convolutions of structural parameters that, by their nature, should be constant over time. Cogley and Sargent(2005), Primiceri (2005) and Sims and Zha(2006) point out to instability of reduced form VARs. Interestingly, the evidence is mixed on the source of instability: Cogley and Sargent(2005) and Primiceri(2005) point toward time variation in parameters and in disturbance variance, while, according to Sims and Zha(2006) the best fit allows time variation in disturbance variances only. Justiniano and Primiceri(2007) and Fernandez-Villaverde and Rubio Ramirez (2007a, 2007b) point out to parameter instability of DSGE models, and the evidence on the sources of instability is similar to that available for reduced form VAR, with Justiniano and Primiceri(2007) highlighting the importance of stochastic volatilities while Fernandez and Rubio Ramirez (2007b) questioning the stability of parameters deemed to be structural.

In the light of this evidence it would be important to consider as a benchmark for model evaluation a more general specification than the one obtained by releasing some coefficient restrictions on a VAR involving only the variables included in a DSGE model. Ideally, we would like to consider as a benchmark a model that parsimoniously includes all the information excluded from the theoretical DSGE. A recent strand of the econometric literature ${ }^{3}$ has shown that very large macroeconomic datasets can be properly modelled using dynamic factor models, where the factors can be considered as an exhaustive summary of the information in the data. The rationale underlying dynamic factor models is that the behavior of several variables is driven by few common forces, the factors, plus idiosyncratic shocks. Hence, the factors can provide an exhaustive summary of the information in large datasets, and in this sense they are precious to alleviate omitted variable problems in empirical analysis using traditional small-scale models, see Bernanke and Boivin (2003). In fact, Bernanke and Boivin (2003), Bernanke, Boivin and Eliasz(2005) proposed to exploit factors

\footnotetext{
${ }^{3}$ Stock and Watson $(2002)$, Forni and Reichlin $(1996,1998)$ and Forni et al. $(1999,2000)$
} 
in the estimation of VAR to generate a more general specification. Chudik and Pesaran (2007) illustrate how a VAR augmented by factor could help in keeping the number of parameters to be estimated under control without loosing relevant information. Boivin and Giannoni(2006) propose a DSGE-FAVAR as a way of removing the assumption that economic variables included in a DSGE are properly measured by a single indicator. The theoretical concepts of the model are treated as partially observed to use the information set in factors to map them. We shall use a factor-augmented VAR (FAVAR) as the relevant statistical model to conduct model evaluation. A FAVAR benchmark for the evaluation of a DSGE model will take the following specification:

$$
\left(\begin{array}{l}
\mathbf{Y}_{t} \\
\mathbf{F}_{t}
\end{array}\right)=\left[\begin{array}{ll}
\boldsymbol{\Phi}_{11}(L) & \boldsymbol{\Phi}_{12}(L) \\
\boldsymbol{\Phi}_{21}(L) & \boldsymbol{\Phi}_{22}(L)
\end{array}\right]\left(\begin{array}{l}
\mathbf{Y}_{t-1} \\
\mathbf{F}_{t-1}
\end{array}\right)+\left(\begin{array}{c}
\mathbf{u}_{t}^{Z} \\
\mathbf{u}_{t}^{F}
\end{array}\right),
$$

where $\mathbf{Y}_{t}$ are the observable variables included in the DSGE model and $\mathbf{F}_{t}$ is a small vector of unobserved factors extracted from a large data-set of macroeconomic time series, that capture additional economic information relevant to model the dynamics of $\mathbf{Y}$

${ }_{t}$. The system reduces to the standard VAR used to evaluate DSGE models if $\boldsymbol{\Phi}_{12}(L)=0$, therefore, within this context, the relevant $\lambda$ test would add to the usual DSGE model-related restrictions on $\boldsymbol{\Phi}_{11}(L)$ the restrictions $\boldsymbol{\Phi}_{12}(L)=0$. To our knowledge, FAVAR have not been so far used to evaluate DSGE, and this is what we shall do in this paper using dynamic factors as the analogue of a richer dynamics for the evaluation of Cowles commission models proposed by Spanos ${ }^{4}$.

Importantly, and differently from Boivin and Giannoni(2006), we do not interpret the FAVAR as the reduced form of a DSGE model at hand. In fact, in this case the restrictions implied by DSGE model on a general FAVAR are very difficult to trace and model evaluation becomes even more difficult to implement. A very tightly parameterized theory model can have a very highly parameterized reduced form if one is prepared to accept that the relevant theoretical concepts in the model are combination of many macroeconomic and financial variables. Identification of the relevant structural parameters, that is very hard also in DSGE model with observed variables (see Canova and Sala,2006), becomes even harder. Natural advantages of this approach are increased efficiency in the estimation of the model and improved forecasting performance. However, model evaluation becomes almost impossible to pursue and a theoretical model can only by rejected by another theoretical model, while the implied statistical model is made so general that virtually no room is left to the data to reject a DSGE model.

\section{Model Evaluation of a Simple DSGE Model}

We consider a small New Keynesian DSGE model of the economy which features a representative household optimizing over consumption, real money holdings

\footnotetext{
${ }^{4}$ In our application we consider a special case of the FAVAR in which $\Phi_{21}(L)=0$
} 
and leisure, a continuum of monopolistically competitive firms with price adjustment costs and a monetary policy authority which sets the interest rate. Furthermore, the model is driven by three exogenous processes which determine government spending, $g_{t}$, the stationary component of technology, $z_{t}$, and the policy shock, $\epsilon_{R, t}$.

A full description of the model can be found in Woodford (2003). Here, we mainly focus on its log-linear representation which takes each variable as deviations from its trend. The model has a deterministic steady state with respect to the de-trended variables: the common component is generated by a stochastic trend in the exogenous process for technology. The model follows Del Negro and Schorfheide (2004) (henceforth, DS) and it reads

$$
\begin{aligned}
\tilde{x}_{t} & =E_{t} \tilde{x}_{t+1}-\frac{1}{\tau}\left(\tilde{R}_{t}-E_{t} \tilde{\pi}_{t+1}\right)+\left(1-\rho_{G}\right) \tilde{g}_{t}+\rho_{z} \frac{1}{\tau} \tilde{z}_{t} \\
\tilde{\pi}_{t} & =\beta E_{t} \tilde{\pi}_{t+1}+\kappa\left(\tilde{x}_{t}-\tilde{g}_{t}\right) \\
\tilde{R}_{t} & =\rho_{R} \tilde{R}_{t-1}+\left(1-\rho_{R}\right)\left(\psi_{1} \tilde{\pi}_{t}+\psi_{2} \tilde{x}_{t}\right)+\epsilon_{R, t} \\
\tilde{g}_{t} & =\rho_{g} \tilde{g}_{t-1}+\epsilon_{g, t} \\
\tilde{z}_{t} & =\rho_{z} \tilde{z}_{t-1}+\epsilon_{z, t}
\end{aligned}
$$

where $\tilde{x}_{t}$ is the output gap, $\tilde{\pi}_{t}$ is the inflation rate, $\tilde{R}_{t}$ is the short-term interest rate and $\tilde{g}_{t}$ and $\tilde{z}_{t}$ are two $\mathrm{AR}(1)$ stationary processes for government and technology, respectively.

The first equation is an intertemporal Euler equation obtained from the households' optimal choice of consumption and bond holdings. There is no investment in the model and so output is proportional to consumption up to an exogenous process that can be interpreted as time-varying government spending. The net effects of these exogenous shifts on the Euler equation are captured in the process $\tilde{g}_{t}$. The parameter $0<\beta<1$ is the households' discount factor and $\tau>0$ is the inverse of the elasticity of intertemporal substitution. The second equation is the forward-looking Phillips curve which describes the dynamics of inflation and $\kappa$ determines the degree of the short-run trade-off between output and inflation.

The third equation describes the behavior of the monetary authority. The central bank follows a nominal interest rate rule by adjusting its instrument to deviations of inflation and output from their respective target levels. The shock $\epsilon_{R, t}$ can be interpreted as unanticipated deviation from the policy rule or as policy implementation error. The set of structural shocks is thus $\epsilon_{t}=$ $\left(\epsilon_{R, t}, \epsilon_{g, t}, \epsilon_{z, t}\right)^{\prime}$ which collects technology, government and monetary shocks.

The model needs to be solved and this can be done by applying the algorithm proposed by Sims (2002). Define the vector of variables as $\tilde{Z}_{t}=$ $\left(\begin{array}{lllllllll}\tilde{x}_{t} & \tilde{\pi}_{t} & \tilde{R}_{t} & \tilde{R}_{t}^{*} & \tilde{g}_{t} & \tilde{z}_{t} & E_{t} \tilde{x}_{t+1} & E_{t} \tilde{\pi}_{t+1}\end{array}\right)$ and the vector of shocks as $\epsilon_{t}=$ $\left(\begin{array}{llll}\epsilon_{R, t} & \epsilon_{g, t} & \epsilon_{z, t}\end{array}\right)$. Therefore the previous set of equations, (11) - (15), can be recasted into a set of matrices $\left(\Gamma_{0}, \Gamma_{1}, C, \Psi, \Pi\right)$ accordingly to the definition of the vectors $\tilde{Z}_{t}$ and $\epsilon_{t}$

$$
\Gamma_{0} \tilde{Z}_{t}=C+\Gamma_{1} \tilde{Z}_{t-1}+\Psi \epsilon_{t}+\Pi \eta_{t}
$$


where $\eta_{t+1}$, such that $E_{t} \eta_{t+1} \equiv E_{t}\left(y_{t+1}-E_{t} y_{t+1}\right)=0$, is the expectations error $^{5}$.

As a solution to (16), we obtain the following policy function

$$
\tilde{Z}_{t}=T(\theta) \tilde{Z}_{t-1}+R(\theta) \epsilon_{t}
$$

and in order to provide the mapping between the observable data and those computed as deviations from the steady state of the model we set the following measurement equations as in DS

$$
\begin{aligned}
\Delta \ln x_{t} & =\ln \gamma+\Delta \tilde{x}_{t}+\tilde{z}_{t} \\
\Delta \ln P_{t} & =\ln \pi^{*}+\tilde{\pi}_{t} \\
\ln R_{t} & =4\left[\left(\ln R^{*}+\ln \pi^{*}\right)+\tilde{R}_{t}\right]
\end{aligned}
$$

which can be also cast into matrices as

$$
Y_{t}=\Lambda_{0}(\theta)+\Lambda_{1}(\theta) \tilde{Z}_{t}+v_{t}
$$

where $Y_{t}=\left(\Delta \ln x_{t}, \Delta \ln P_{t}, \ln R_{t}\right)^{\prime}, v_{t}=0$ and $\Lambda_{0}$ and $\Lambda_{1}$ are defined accordingly. For completeness, we write the matrices $T, R, \Lambda_{0}$ and $\Lambda_{1}$ as a function of the structural parameters in the model, $\theta=\left(\ln \gamma, \ln \pi^{*}, \ln r^{*}, \kappa, \tau, \psi_{1}, \psi_{2}, \rho_{R}, \rho_{g}, \rho_{Z}, \sigma_{R}, \sigma_{g}, \sigma_{Z}\right)^{\prime}$ : such a formulation derives from the rational expectations solution.

The evolution of the variables of interest, $Y_{t}$, is therefore determined by (17) and (21) which impose a set of restrictions across the parameters on the moving average (MA) representation. Given that the MA representation can be very closely approximated by a finite order VAR representation, DS propose to evaluate the DSGE model by assessing the validity of the restrictions imposed by such a model with respect to an unrestricted VAR representation. The choice of the variables to be included in the VAR is however completely driven by those entering in the DSGE model regardless of the statistical goodness of the unrestricted VAR.

The model evaluation method proposed by DS is based on a mixed estimation which combines the data information with the prior information deriving from the DSGE model. The source for the data information is the unrestricted VAR process for all variables included in the DSGE model. The measurement, (21), and the transition, (17), equation can be used to derive a sample of artificial data which are theory driven. This is effectively a set of dummy observations which can be added to the observables data as in Sims and Zha $(1998)^{6}$ to derive a prior distribution for the VAR coefficients. Furthermore, such a prior would be conjugate and that is relevant to keep tractability of the posterior analysis.

A further step would be to compute the posterior distribution for $\left(\Phi, \Sigma_{e}, \theta\right)$. Such a posterior can be written as

$$
P\left(\Phi, \Sigma_{e}, \theta \mid Y\right)=P_{\Phi}\left(\Phi, \Sigma_{e} \mid \theta, Y\right) \times P_{\theta}(\theta \mid Y),
$$

\footnotetext{
${ }^{5}$ See Appendix A for a detailed derivation.

${ }^{6}$ We follow DS and work with population moments instead of artificial data generated from the restricted $\operatorname{VAR}(1)$ to avoid stochastic variation.
} 
where the first component can be easily calculated by using the conjugacy property of the DSGE-based prior while the second one, $P(\theta \mid Y)$, will be derived by recalling MCMC methods. In particular, following DS, the Metropolis-Hastings will be employed to approximate the posterior. The posterior mean of the estimated coefficients is governed by the parameter $\lambda$, a tightness parameters which determines the weight of the DSGE model in the posterior estimates. For instance, as $\lambda \rightarrow 0$, which means no artificial data from the DSGE, the posterior estimates will be equal to the maximum likelihood estimates of the unrestricted VAR since the prior would be flat. ${ }^{7}$ Alternatively, as $\lambda \rightarrow \infty$ we have the posterior driven by the DSGE model only. Therefore the $\lambda$ that maximizes the data density is a natural criterion to assess the DSGE model against the VAR benchmark. ${ }^{8}$ To sum up model evaluation requires to simulate from the posterior distribution of $\theta$ and this results is obtained by going through a number of steps $^{9}$ :

1. Set a value of $\lambda$ or assume a discrete grid over which to run the computation;

2. Solve the DSGE model and get the population moments used in the prior;

3. Given $\lambda$, find the posterior moments for $\left(\Phi, \Sigma_{e}\right)$ and the marginal data density $P(Y \mid \theta)$;

4. Construct the kernel of the posterior for $\theta, P_{Y}(Y \mid \theta) \times P(\theta)$;

5. Apply the $\mathrm{MH}$ acceptance method in order to generate a Markov chain from the posterior distribution of $\theta$;

6. By applying the Gelfand-Dey(1994) method, with the correction proposed by Geweke(1999), compute the marginal data density of the model for each $\lambda$;

7. Compare such marginal densities over the discrete grid of $\lambda$. Model validation requires $\lambda$ that maximizes the data density.

\section{DSGE Model Evaluation and Statistical Iden- tification.}

The evaluation of DSGE models based on the $\lambda$ parameter is based on the choice of a VAR derived by relaxing the theoretical restrictions as a statistical benchmark. This choice closely resemble the approach taken by the Cowles Commission to evaluate structural econometric models: the chosen benchmark,

\footnotetext{
${ }^{7}$ The Jeffrey's prior we used for the DSGE based prior.

${ }^{8}$ See Appendix $\mathrm{C}$ for a detailed description of how draws from the posterior distribution are generated.

${ }^{9}$ Details of the derivation of the relevant posterior are described in Appendix C.
} 
being driven the specification of the structural model adopted, could very well lack of statistical identification.

To evaluate the potential relevance of this problem we propose to base the evaluation of the DSGE model on a model-independent benchmark, which is based on a larger information set than the VAR driven by the DSGE model specification.

We consider the case in which additional economic information, not fully captured by $\mathbf{Y}_{t}$, is relevant to modelling the dynamics of inflation output growth and the monetary policy rate. These additional information can be summarized in a (small) $(k x 1)$ vector of unobserved factors $\mathbf{F}_{t}$.

We then adopt a Factor Augmented VAR as our benchmark model:

$$
\left(\begin{array}{c}
\mathbf{Y}_{t} \\
\mathbf{F}_{t}
\end{array}\right)=\left[\begin{array}{ll}
\mathbf{\Phi}_{11}(L) & \boldsymbol{\Phi}_{12}(L) \\
\mathbf{\Phi}_{21}(L) & \mathbf{\Phi}_{22}(L)
\end{array}\right]\left(\begin{array}{c}
\mathbf{Y}_{t-1} \\
\mathbf{F}_{t-1}
\end{array}\right)+\left(\begin{array}{c}
\mathbf{u}_{t}^{Z} \\
\mathbf{u}_{t}^{F}
\end{array}\right)
$$

The system reduces to the standard VAR used to evaluate DSGE models if $\boldsymbol{\Phi}_{12}(L)=0$, therefore, within this context, the relevant $\lambda$ test would add to the usual DSGE model-related restrictions on $\boldsymbol{\Phi}_{11}(L)$ the restrictions $\boldsymbol{\Phi}_{12}(L)=0$.

The implementation of the Bayesian framework described for the evaluation of the DSGE model is altered only as far the likelihood function is concerned, where the more general FAVAR specification substitutes the VAR model (??).

Factors can be constructed following a very recent strand of the econometric literature which has shown that very large macroeconomic datasets can be properly modelled using dynamic factor models, where the factors can be considered as an exhaustive summary of the information in the data.

We extract factors from "informational" time series included in $(N x 1)$ vector $X_{t}$, that consists of a balanced panel of 131 monthly macroeconomic time-series (updates of the series used in Stock and Watson(2002)). The number of informational time series $N$ is large (larger than time period $T$ ) and must be greater than the number of factors and observed variables in the FAVAR system $(k+M \ll N)$.

We estimate our FAVAR by implementing a two-step estimation (Bernanke, Boivin and Eliasz (2005)).

We assume that the informational time series $X_{t}$ are related to the unobservable factors $F_{t}$ by the following observation equation:

$$
X_{t}=\Lambda^{f} \mathbf{F}_{t}+e_{t}
$$

where $\mathbf{F}_{t}$ is a $r \times 1$ vector of common factors, $\Lambda^{f}$ is a $(N x k)$ matrix of factor loadings, $\Lambda^{y}$ is $(N x M)$ and the $(N x 1)$ vector of error terms $e_{t}$ are mean zero and are normal and uncorrelated or with a small cross-correlation, in fact, the estimator we employ allows for some cross-correlation in $e_{t}$ that must vanish as $N$ goes to infinity. Note that this representation nests also models where $X_{t}$ depends on lagged values of the factors, see Stock-Watson(2002) for details.

In the first step factors are obtained from the observation equation by imposing the orthogonality restriction $F^{\prime} F / T=I$. This implies that $\widehat{F}=\sqrt{T} \widehat{G}$, where the $\widehat{G}$ are the eigenvectors corresponding to the $K$ largest eigenvalues of 
$X X^{\prime}$, sorted in descending order. Stock and Watson (2002) showed that the factors can be consistently estimated by the first $r$ principal components of $X$, even in the presence of moderate changes in the loading matrix $\Lambda$. For this result to hold it is important that the estimated number of factors, $k$, is larger or equal than the true number, $r$.

In the second step, we estimate the FAVAR equation replacing $\mathbf{F}_{t}$ by $\widehat{\mathbf{F}_{t}}$. We shall then compare the VAR and the FAVAR and complete the analysis by considering a DSGE-VAR and a DSGE-FAVAR.

The standard VAR adopted as a benchmark to assess DSGE models is a nested model into FAVAR structure. The FAVAR structure is a richer specification than parsimoniously summarizes a much larger information set than that considered in the VAR.

We shall use the FAVAR for evaluating the statistical identification of the VAR by taking several steps.

First, we shall assess directly the significance of coefficient on factors and compare the goodness of fit of the FAVAR with respect to that of the VAR. We shall also evaluate how different is impulse response analysis based on the VAR and on the FAVAR to see how different is the description of the economy offered by the two alternative models.

Second, the two alternative models will be analyzed by assessing via appropriate tests, as suggested by Spanos(1990), the properties of homoskedasticity, serial correlation and normality of the residuals.

Third, the out-of-sample forecasting performance of the alternative models will be assessed by evaluating the RMSE of the FAVAR, the VAR, and the DSGE to assess the relevance of the information progressively discarded by the different models in forecasting the macroeconomic variables of interest.

Finally, the DSGE-FAVAR will be used as a benchmark for the implementation of the lambda test proposed by Del Negro-Schorfheide(2004) to assess how the optimal lambda is influenced by the choice of the FAVAR rather than the VAR as a statistical model to be combined with the DSGE.

\section{Empirical Results}

\subsection{The Data}

We analyse the DSGE-VAR model proposed by Del Negro and Schorfheide (2004) (DS). DS based their analysis on U.S. quarterly data from 1955:III to 2001:III, they also analyse separately the 1955-1979 period and the 1980-2001 period. We concentrate on the second subsample to keep comparability between our DSGE-FAVAR and the original DS DSGE-VAR whilst using a sample period which has experienced a more stable monetary and financial structure and a lesser volatility of macroeconomic variables period. Structural breaks in mean and volatility are found in the literature by comparing the pre- 80 with the post- 80 period, while the null hypothesis of parameters' stability cannot be rejected in the post 80 period (see Justiniano and Primiceri (2007)), moreover 
inflation, the monetary policy rate and annual real output growth, i.e. all variables included in the empirical specification, are clearly mean reverting in the post 1980 period. This evidence should reduce the concern of having a nonstationary VAR that omits potential long-run cointegrating relations among the variables of interest. The data for real output growth come from the Bureau of Economic Analysis (Gross Domestic Product-SAAR, Billions Chained 1996\$). The data for inflation come from the Bureau of Labor Statistics (CPI-U: All Items, seasonally adjusted, 1982-1984=100). GDP and CPI are taken in first difference of logarithmic transformation. The interest rate series are constructed as in Clarida, Galì and Gertler (2000), for each quarter the interest rate is computed as the average federal funds rate (source: Haver Analytics) during the first month of the quarter, including business days only. The lag length in the VAR is four quarters. In order to construct the FAVAR we proceed to extract factors from a balanced panel of 131 monthly macroeconomic and financial time series (Stock and Watson (1999)) The dataset involves several measures of industrial production, interest rates,various price indices, employment as well as other important macroeconomic and also financial variables. This panel data is in monthly format, we transform it into a quarterly dataset using end-of-period observations. All series have been transformed to induce stationarity. The series are taken into level, logarithms, first or second difference (in level or logarithms) according to series characteristics (see the Appendix for a description of all series and details of the transformations). Following Bernanke, Boivin and Eliasz (2005) we partition the data in two categories of information variables: slow and fast. The partitioning is crucial to identify shocks necessary to construct impulse response functions in our FAVAR. Slow-moving variables (for example, wages or spending) do not respond contemporaneously to unanticipated changes in monetary policy; while fast-moving variables (for example, asset prices and interest rates) do respond contemporaneously to monetary shocks (see again the Appendix for further details ).

We proceed to extract two factors from slow variables and one factor from fast variables and we call them respectively "slow factors" and "fast factor". ${ }^{10}$ We extract factors by using principal components. Stock-Watson(1998) showed that the factors can be consistently estimated by the first $r$ principal components of $X$, even in the presence of moderate changes in the loading matrix $\Lambda$. For this result to hold it is important that the estimated number of factors, $k$, is larger or equal than the true number, $r$. Bai and $\mathrm{Ng}$ (2000) proposed a set of selection criteria to choose $k$ that are generalizations of the BIC and AIC criteria. As suggested by Bai and $\mathrm{Ng}(2000)$ we use information criteria to determine the number of factors but, as they are not so decisive, we limit the number of factors to three to strike a balance between the variance of the original series explained by the principal components and the difference in the parameterization of the

\footnotetext{
${ }^{10}$ We extract factors by using principal components. As suggested by Bai and $\mathrm{Ng}(2000)$ we use information criteria to determine the number of factors but, as they are not so decisive, we limit the number of factors to three to strike a balance between the variance of the original series explained by the principal components and the difference in the parameterization of the VAR and the FAVAR.
} 
VAR and the FAVAR. It is also worth noting that the factors are not uniquely identified, but this is not a problem in our context because we will not attempt a structural interpretation of the estimated factors. Finally, having determined the number of factors, we specify a Factor Augmented VAR by considering fourlags of the factors to keep the same lag-order chosen by DS for the VAR, we also consider a more parsimonious parameterization in which only one-lag of the factors is included.

\subsection{The DSGE-VAR}

We consider a benchmark DSGE-VAR model that replicates the results reported in Del Negro and Schorfheide (2004). As discussed in the previous section we report estimates for the DSGE-VAR over the sample 1981-2001, considering the DSGE model described in section 2 and a four-order VAR for the vector $Y_{t}=\left(\Delta \ln x_{t}, \Delta \ln P_{t}, \ln R_{t}\right)^{\prime}$. We report in Table 1 reports Prior and Posterior for DSGE model parameters that are calibrated to generate posterior means and intervals as in Table 2 in Del Negro and Schorfheide (2004).

TABLE 1: Prior and Posterior of DSGE Model Parameters 1981-2001

\begin{tabular}{|c|c|c|c|c|c|c|c|c|c|c|}
\hline & Prior & \multicolumn{2}{|c|}{ Posterior } & \multicolumn{2}{c|}{ Posterior } & \multicolumn{2}{c|}{ Posterior } & \multicolumn{2}{c|}{ Posterior } \\
\hline & & & \multicolumn{2}{|c|}{$(\lambda=0.2)$} & \multicolumn{2}{c|}{$\left(\lambda^{*}=0.6\right)$} & \multicolumn{2}{c|}{$(\lambda=1)$} & \multicolumn{2}{c|}{$(\lambda=10)$} \\
\hline & LOW & UPP & LOW & UPP & LOW & UPP & LOW & UPP & LOW & UPP \\
\hline $\ln \gamma$ & 0.101 & 0.922 & 0.314 & 0.923 & 0.378 & 0.926 & 0.388 & 0.914 & 0.440 & 0.859 \\
\hline $\ln \pi^{*}$ & 0.219 & 1.863 & 0.511 & 1.112 & 0.503 & 1.080 & 0.474 & 1.087 & 0.288 & 1.548 \\
\hline $\ln r^{*}$ & 0.132 & 0.880 & 0.144 & 0.746 & 0.186 & 0.757 & 0.234 & 0.789 & 0.500 & 0.866 \\
\hline$\kappa$ & 0.063 & 0.513 & 0.144 & 0.701 & 0.198 & 0.804 & 0.236 & 0.820 & 0.062 & 0.405 \\
\hline$\tau$ & 1.197 & 2.788 & 1.167 & 2.674 & 1.170 & 2.475 & 1.114 & 2.604 & 2.005 & 3.601 \\
\hline$\psi_{1}$ & 1.121 & 1.910 & 1.010 & 1.643 & 1.005 & 1.522 & 1.000 & 1.539 & 0.999 & 1.366 \\
\hline$\psi_{2}$ & 0.001 & 0.260 & 0.111 & 0.524 & 0.165 & 0.699 & 0.174 & 0.663 & 0.240 & 0.617 \\
\hline$\rho_{R}$ & 0.157 & 0.812 & 0.402 & 0.791 & 0.488 & 0.756 & 0.530 & 0.751 & 0.723 & 0.837 \\
\hline
\end{tabular}

Notes: LOW and UPP are the lower and the upper bounds of the $90 \%$ confidence intervals based on the output of the Metropolis-Hastings Algorithm.

We then conduct DSGE model evaluation by determining $\widehat{\lambda}$ using the grid $\Lambda=\{0.20,0.60,1,1.4,1.8,10, \operatorname{Inf}\}$. The minimum value of $\lambda$ satisfying the lower bound restriction $\lambda \geq \frac{k+m}{T}$ with $k=13, m=3$ and $T=80$ is $\lambda_{\min }=.20$. Figure 1 reports the results of the grid search that deliver 0.60 as the optimal $\lambda$ in case we use Metropolis-Hastings Algorithm 100000 replications ${ }^{11}$.

\section{Insert Figure 1 here}

\footnotetext{
${ }^{11}$ Slightly different results are obtained when using 25000 replications, as the mapping between lambda and the marginal data density is not as smooth as with 100000 replications.
} 
Note that the weight attached to the DSGE is $\frac{\lambda}{1+\lambda}$ so $\lambda^{*}=.60$ implies a weight of 0.375 on the DSGE model and therefore the size of the artificial sample generated by the DSGE should be of sixty per cent of the size of the sample of genuine observations. On the basis of very similar evidence Del Negro, Schorfheide, Smets and Wouters (2006) conclude that "...the degree of misspecification in DSGE models is no longer so large to prevent their use in day-to-day policy analysis, yet it is not so small that it cannot be ignored....".

\subsection{The Statistical Identification of the DSGE-VAR}

We begin our assessment of the statistical identification of the VAR used to construct the DSGE-VAR model by illustrating the statistical evidence on the augmentation of the VAR with factors.

In practice, we consider the extension of the baseline VAR model:

$$
\begin{aligned}
\mathbf{Y}_{t} & =\sum_{i=1}^{4} A_{i} Y_{t-i}+\mathbf{u}_{t}^{Y} \\
Y_{t} & =\left(\Delta \ln x_{t}, \Delta \ln P_{t}, \ln R_{t}\right)
\end{aligned}
$$

to the following FAVAR model

$$
\begin{aligned}
\left(\begin{array}{c}
\mathbf{Y}_{t} \\
\mathbf{F}_{t}
\end{array}\right) & =\left[\begin{array}{ll}
\mathbf{\Phi}_{11}(L) & \mathbf{\Phi}_{12}(L) \\
\mathbf{\Phi}_{21}(L) & \mathbf{\Phi}_{22}(L)
\end{array}\right]\left(\begin{array}{l}
\mathbf{Y}_{t-1} \\
\mathbf{F}_{t-1}
\end{array}\right)+\left(\begin{array}{c}
\mathbf{u}_{t}^{Y} \\
\mathbf{u}_{t}^{F}
\end{array}\right) \\
\mathbf{Y}_{t} & =\left(\Delta \ln x_{t}, \Delta \ln P_{t}, \ln R_{t}\right) \\
\mathbf{F}_{t} & =\left(F_{1 t}^{s}, F_{2 t}^{s}, F_{3 t}^{f}\right)
\end{aligned}
$$

where $F_{1 t}^{s}, F_{2 t}^{s}$ are the two slow factors and $F_{3 t}^{f}$ is the fast factor. $\boldsymbol{\Phi}_{11}(L), \boldsymbol{\Phi}_{12}(L), \boldsymbol{\Phi}_{22}(L)$ are polynomial of order four in the lag factor for our benchmark parameterization. We experiment also with having $\boldsymbol{\Phi}_{12}(L), \boldsymbol{\Phi}_{22}(L)$ as polynomial of order one.

Table 2 compares the VAR and FAVAR specifications for the vector $\mathbf{Y}_{t}=$ $\left(\Delta \ln x_{t}, \Delta \ln P_{t}, \ln R_{t}\right)$, considering two alternative FAVARs' including respectively one lag(FAVAR(1)) and four lags(FAVAR(4)) of the factors .

\begin{tabular}{||l|l|l|l|l|}
\hline \hline \multicolumn{5}{|c|}{ TABLE 2: VAR and FAVAR specifications: 1981-2001 } \\
\hline \hline Equation & & $\Delta \ln x_{t}$ & $\Delta \ln P_{t}$ & $\ln R_{t}$ \\
\hline & Adj R & 0.39 & 0.30 & 0.93 \\
\hline VAR & S.E. & 0.54 & 0.32 & 0.69 \\
\hline & Adj R & 0.39 & 0.43 & 0.98 \\
\hline FAVAR(4) & S.E. & 0.54 & 0.29 & 0.46 \\
\hline & $\chi^{2}(12)$ & 13.05 & 27.88 & 99.77 \\
& Adj R $^{2}$ & 0.36 & 0.006 & 0.000 \\
\hline & SAVAR $(1)$ & 0.50 & 0.44 & 0.97 \\
\hline & $\chi^{2}(3)$ & 14.02 & 20.08 & 0.47 \\
& & 0.002 & 0.0002 & 0.000 \\
\hline
\end{tabular}


The results reported in Table 2 clearly illustrate that factors are jointly significant in the specification for all three variables included in the baseline VAR, the only exception being the specification for the output growth equation when four lags of three factors are considered.

Table 3.1-3.3 report the evidence on the residual analysis from the VAR, the FAVAR(1) and the FAVAR(4). Table 3.1 reports the outcome of the JarqueBera(1980) tests of the null hypothesis of normality of residuals from each equation and for the joint three-equation model.

\begin{tabular}{|l|l|l|l|l|l|}
\hline \multicolumn{6}{|c|}{ TABLE 3.1: Normality of Residuals } \\
\hline Equation & & $\Delta \ln x_{t}$ & $\Delta \ln P_{t}$ & $\ln R_{t}$ & Joint \\
\hline & Jarque-Bera & $\chi^{2}(2)$ & $\chi^{2}(2)$ & $\chi^{2}(2)$ & $\chi^{2}(6)$ \\
\hline VAR & & 5.72 & 5.03 & 0.40 & 11.17 \\
\hline FAVAR(4) & & 0.08 & 0.06 & 0.82 & 0.08 \\
\hline FAVAR(1) & & 0.505 & 2.52 & 8.76 & 21.79 \\
& & 6.48 & 1.13 & 0.01 & 0.001 \\
\hline
\end{tabular}

The null of normality is not rejected for the VAR and FAVAR(1) while it is rejected in the case of the FAVAR(4), the main cause of this rejection is the non-normality of residuals in the output growth equation. However, departure from the null hypothesis of normality of the size described by Table 3 has been shown to be very little relevant for the Bayesian analysis of the optimal $\lambda$, (see Christiano(2007)).

Table 3.2 reports the outcome of Breusch-Godfrey ${ }^{12}$ Lagrange Multiplier test for autocorrelation of residuals at all lags from one to four.

\begin{tabular}{|l|c|l|l|l|}
\hline \multicolumn{5}{|c|}{ TABLE 3.2: Serial Correlation of Residuals } \\
\hline LM $\chi^{2}(9)$ & LAG 1 & LAG 2 & LAG 3 & LAG 4 \\
\hline & & & & \\
\hline VAR & 31.43 & 29.37 & 8.58 & 7.28 \\
& 0.0002 & 0.0006 & 0.48 & 0.60 \\
\hline FAVAR(4) & 11.97 & 8.44 & 13.06 & 12.77 \\
\hline FAVAR(1) & 0.21 & 0.49 & 0.16 & 0.17 \\
& 0.23 & 15.14 & 10.17 & 6.43 \\
\hline
\end{tabular}

Here the results points toward strong evidence of residual autocorrelation in the VAR specification while the null hypothesis of absence of residual correlation at any lags cannot be rejected in the $\operatorname{FAVAR}(1)$ and the $\operatorname{FAVAR}(4)$ specifications.

\begin{tabular}{|l|l|l|l|}
\hline \multicolumn{4}{|c|}{ TABLE 3.3: Homoscedasticity of Residuals } \\
\hline White test & VAR & FAVAR(4) & FAVAR(1) \\
\hline & $\chi^{2}(144)$ & $\chi^{2}(288)$ & $\chi^{2}(180)$ \\
\hline & 172 & 290 & 208 \\
\hline & 0.05 & 0.44 & 0.08 \\
\hline
\end{tabular}

\footnotetext{
${ }^{12}$ See Godfrey(1988).
} 
Table 3.3 reports the outcome of the White(1980) heteroscedasticity tests on the residuals of the trivariate system. Once again while the null of homoscedasticity cannot be rejected in the FAVAR(4) and the FAVAR(1) specification, it is rejected at the five per cent level in the VAR specification. To further assess the stability of the variance-covariance matrix of residuals in our specifications we have estimated a diagonal BEKK (Engle and Kroner 1995) allowing for a multivariate GARCH in the vector of residuals. Defining as $\Sigma_{t}$ the (potentially) time-varying variance-covariace of residuals, BEKK is defined as:

$$
\Sigma_{t}=\Omega \Omega^{\prime}+A \mathbf{u}_{t-1} \mathbf{u}_{t-1}^{\prime} A^{\prime}+B \Sigma_{t-1} B
$$

where $\mathbf{u}_{t-1}$ is the vector of residuals from the relevant model and the $A, B$ are restricted to be diagonals. In the case of the FAVARs there are no significant coefficients in the $A$ matrices, while these coefficients are significant in the VAR specification $^{13}$. This evidence confirms the findings in Giannone et al.(2008) that find that time-varying pattern in volatility of the shocks is a feature of small system that might disappear when the information set is enlarged.

We proceed to a further comparative analysis of the VAR and the FAVAR models by considering impulse response function to a monetary policy shock. Monetary policy shocks are identified in the VAR by assuming that the macroeconomic variables, inflation and output growth, take at least one period before responding to monetary policy while monetary policy is allowed to react simultaneously to macroeconomic variables. In the FAVAR identification is achieved by extending the VAR assumptions for macroeconomic variables and interest rates to slow factor and by assuming that the fast factor responds contemporaneously to all other variables in the system and that monetary policy does not contemporaneously react to the fast factor.

We plot in Figure 2 we plot responses for an horizon of 20 periods of quarterly inflation, quarterly output growth and the Federal Fund Rates to a monetary shock as derived in the VAR and in the FAVAR(4) estimated over the usual sample impulse in case of VAR and FAVAR for the usual sample 1981-2001. We also report one-standard deviation confidence intervals for the VAR estimation.

\section{Insert Figure 2 here}

The impulse responses show virtually no difference between the VAR and the FAVAR in the case of output growth, while in there are some differences in the case of inflation and the Federal Fund. In the case of inflation the FAVAR does not deliver the initial "price puzzle" that is observed with VAR based impulse responses and the negative dynamic response of inflation to a restrictive monetary policy at the one-year horizon is much more pronounced in the FAVAR case. In the case of the Federal Fund rate a much less persistent profile is observed in the FAVAR specification.

We complete our traditional evaluation of alternative models by considering the out-of-sample forecasting performance of the VAR, the FAVAR and the

\footnotetext{
${ }^{13}$ Results of the BEKK estimation are available upon request
} 
DSGE models. Given estimation of all models over the sample 1981:1-1997:4, we consider the out-of-sample performance for the period 1998:1-2001:4. In particular, we concentrate on the Root Mean Squared Error of the forecasting errors from the different model, computed as follows:

$$
\begin{aligned}
R M S E^{y} & =\sqrt{\frac{1}{16} \sum_{h=1}^{16}\left(y_{t+h}-\hat{y}_{t+h \mid t}\right)^{2}} \\
y & =\Delta \ln x_{t}, \Delta \ln P_{t}, \ln R_{t}, \\
t & =1997: 4
\end{aligned}
$$

where $\hat{y}_{t+h \mid t}$ is the mean forecast computed as the average across draws and.

\begin{tabular}{|c|c|c|c|}
\hline TABLE 4: The Forec & $\overline{\text { ng Perfo }}$ & $\operatorname{anc}$ & tive $r$ \\
\hline MODEL & $\Delta \ln x_{t}$ & $\Delta \ln P_{t}$ & $\ln R_{t}$ \\
\hline & $R M S E$ & $R M S E$ & $R M S E$ \\
\hline $\operatorname{VAR}(4)$ & 0.63 & 0.29 & 0.88 \\
\hline $\operatorname{FAVAR}(4,4)$ & $\begin{array}{l}0.56 \\
(0.89)\end{array}$ & $\begin{array}{c}0.24 \\
(0.82)\end{array}$ & $\begin{array}{l}0.92 \\
(1.05)\end{array}$ \\
\hline $\operatorname{FAVAR}(4,1)$ & $\begin{array}{l}0.57 \\
(0.92) \\
\end{array}$ & $\begin{array}{c}0.24 \\
(0.82) \\
\end{array}$ & $\begin{array}{r}0.83 \\
(0.94) \\
\end{array}$ \\
\hline DSGE & $\begin{array}{c}0.63 \\
(1.01)\end{array}$ & $\begin{array}{c}0.24 \\
(0.83)\end{array}$ & $\begin{array}{c}0.80 \\
(0.91)\end{array}$ \\
\hline $\operatorname{DSGE-VAR}\left(\lambda^{*}=0.6\right)$ & $\begin{array}{l}0.61 \\
(0.97) \\
\end{array}$ & $\begin{array}{r}0.25 \\
(0.86) \\
\end{array}$ & $\begin{array}{l}0.80 \\
(0.91) \\
\end{array}$ \\
\hline RMSE relative to the $\mathrm{V}$ & within & ackets & \\
\hline$\overline{\mathrm{FAT}}$ & the & & \\
\hline
\end{tabular}
$t=1997: 4$.

We report the results of our analysis in Table 4.

Our results clearly favour the FAVAR against the VAR, moreover the improvements in the forecasting performance achieved by the DSGE and the $\operatorname{DSGE}-\operatorname{VAR}\left(\lambda^{*}=0.6\right)$ against the VAR are not obtained when the FAVARs are considered as benchmarks.

\subsection{A FAVAR Analysis of the Simple DSGE Model}

In the light of the evidence reported in the previous section it seems interesting to apply the mixed estimation technique to evaluate the properties of the DSGE-FAVAR instead of the DSGE-VAR. The FAVAR has the interesting properties of being an empirical model that is based on information independent from the theoretical model and it does then constitute a model whose statistical identification is independent of the validity of unrestricted VAR underlying the solution of the adopted theoretical model. In fact, we have shown for our particular application that a FAVAR which augments the VAR(p) specification for the variables in the theoretical model with a set of factors extracted from a large information set improves considerably on the VAR in terms of statistical adequacy. 
In this case the benchmark specification for the unrestricted dynamics of the variables included in the theoretical model becomes the following:

$$
Y_{t}=B_{0} X_{t}+B_{1} F_{t}+E_{t}
$$

where $\mathbf{Y}_{t}=\left(\Delta \ln x_{t}, \Delta \ln P_{t}, \ln R_{t}\right), X_{t}=\left[1, \mathbf{Y}_{t-1}, \ldots \mathbf{Y}_{t-p}\right], F_{t}=\left[f_{t}^{\prime}, f_{t-1}^{\prime}, \ldots f_{t-q}^{\prime}\right]^{\prime}$ groups $q$ lags of the three factors $f_{t}=\left[f_{1, t}, f_{2, t}, f_{3, t}\right]^{\prime}$ extracted and interpreted as in Bernanke, Boivin and Eliasz (2005), $E_{t}$ is the three-variate vector of innovations. System (59) can be re-written in a more compact form as follows:

$$
Y_{t}=B W_{t}+E_{t}
$$

where $B=\left[B_{0}, B_{1}\right]$ is of dimension $m \times(1+m p+r q)$ and $W_{t}=\left[X_{t}^{\prime}, F_{t}^{\prime}\right]^{\prime}$.

At this stage the derivation of the likelihood function resembles very closely the simpler case discussed in section 3. However, there are some differences in terms of the prior and the posterior distribution between the DSGE-VAR and the DSGE-FAVAR. We report in Appendix B the technical discussion of these derivation. Posterior calculations are similar to those discussed in the case of the DSGE-VAR, however in this case the parameter $\lambda$ captures the relative weight of the information coming from the FAVAR and from the theoretical model.

The parameter $\lambda$ is chosen from an interval which is unbounded from above. In our empirical exercise we will be using a discrete grid over which we will compute the marginal data density, $P(Y \mid \lambda)$. The minimum value, $\lambda_{\min }=$ $\frac{m+k}{T}$, is model dependent and it is related to the existence of a well-defined Inverse-Wishart distribution. For completeness, it is worth to mention that $\lambda=0$ refers to the FAVAR model with no prior and it is not possible to compute the marginal likelihood in this particular case. Therefore, we can show the marginal data density for any value of $\lambda$ larger than $\lambda_{\min }$.Importantly $\lambda_{\min }$ depends on the degrees of freedom in the FAVAR and therefore, given estimation on the same number of available observation, $\lambda_{\min }$ for a DSGE-FAVAR will always be larger that $\lambda_{\min }$ for a DSGE-VAR.

Figure 3 shows the marginal likelihood for different $\lambda$, when a $\operatorname{FAVAR}(4,1)$ is considered as the baseline statistical model. The optimal value turn out to be $\lambda^{*}=0.60$, as in the case of the DSGE-VAR. Of course, the distance between the optimal $\lambda$ and $\lambda_{\min }$ is smaller in the DSGE-FAVAR than in the DSGE-VAR but still the lambda test indicates that the size of the artificial sample generated by the DSGE should be of sixty per cent of the size of the sample of genuine observations generated from the FAVAR model. In the case of a $\operatorname{FAVAR}(4,4)$, $\lambda^{*}=1.4$ and the size of the artificial sample generated by the DSGE should now be greater than the size of the sample of genuine observations generated from the FAVAR model. Also in this case $\lambda_{\text {min }}$ is higher than in our benchmark case as a consequence of the more generous parameterization of the DSGE-FAVAR $(4,4)$.

To provide further evidence of the performance of the DSGE evaluated on the basis of the FAVAR, Table 5 considers the Forecasting performance of the VAR, the FAVAR and the optimal combination between DSGE and FAVAR. 


\begin{tabular}{|l|c|c|c|c|}
\hline TABLE 5: The Forecasting Performance of FAVAR and DSGE-FAVAR \\
\hline MODEL & $\Delta \ln x_{t}$ & $\Delta \ln P_{t}$ & $\ln R_{t}$ \\
\hline & & $R M S E$ & $R M S E$ & $R M S E$ \\
\hline VAR $(4)$ & 0.63 & 0.29 & 0.88 \\
\hline FAVAR $(4,4)$ & 0.56 & 0.24 & 0.92 \\
& $(0.89)$ & $(0.82)$ & $(1.05)$ \\
\hline FAVAR $(4,1)$ & 0.57 & 0.24 & 0.83 \\
& $(0.92)$ & $(0.82)$ & $(0.94)$ \\
\hline DSGE-FAVAR $(4,4)\left(\lambda^{*}=1.4\right)$ & 0.55 & 0.23 & 0.75 \\
& $(0.88)$ & $(0.79)$ & $(0.85)$ \\
\hline DSGE-FAVAR $(4,1)\left(\lambda^{*}=0.6\right)$ & 0.58 & 0.24 & 0.76 \\
& $(0.93)$ & $(0.80)$ & $(0.87)$ \\
\hline RMSE relative to the VAR(4) within brackets \\
\hline
\end{tabular}

The evidence reported shows that best forecasting performance is achieved by the optimal combination of the DSGE and the FAVAR. As final evaluation criterion, consistent with the Bayesian estimation procedure, we have considered the odds ratio between the DSGE-VAR and the DSGE FAVAR. The odds ratio compares marginal data density associated to alternative models, the traditional rule of thumb suggest to favour a model with respect to a competitor if its marginal data density is larger than three times that of its competitor. In our case the log of marginal likelihood of the DSGE-VAR in correspondence of the optimum $\lambda$ is -215 while that of the DSGE-FAVAR $(4,1)$ at the same $\lambda$ is of 197.5. This implies that the odds ratio in log terms take the value of 17.5 , clearly favouring the DSGE-FAVAR. Similar results are obtained by comparing the DSGE-FAVAR $(4,4)$ with the DSGE-VAR. Importantly the comparison between Figure 1 and Figure 3 suggests that the dominance of the DSGE-FAVAR over the DSGE-VAR in terms of the posterior odds ratio is not limited to the optimal value of $\lambda$ but it is independent from the choice of a particular value for $\lambda$. Overall, our results suggest that using a more general statistical model than that derived simply by relaxing restrictions from the solved theoretical model is important along two dimensions. First, it allows a further evaluation of the DSGE model against a larger information set. Second, in the case some support for the DSGE model is found in the data when evaluated against the larger information set (the optimal $\lambda$ in the DSGE-FAVAR is different from zero), the optimal combination between the DSGE model and the statistical model based on a larger information set (the FAVAR) delivers a forecasting model (the DSGE-FAVAR) that dominates all alternatives.

\section{Conclusions}

In this paper we have analyzed the statistical identification of DSGE models by assessing if an unrestricted VAR constructed by relaxing cross-equation restrictions on the autoregressive approximation to the solution of a DSGE model is an appropriate statistical model. We have considered, as an alternative to the VAR, a FAVAR that uses a few factors to incorporate in the statistical model all the macroeconomic and financial information left out of the DSGE model. 
Our application shows that, FAVAR models dominate VAR specification generated by adopting unrestricted version of the solution of DSGE models. Such dominance is clearly established by analysis of residuals and evaluation of forecasting performance. When we proceed to evaluate DSGE using FAVAR rather than VAR as statistical benchmark we find that some support for the DSGE model is still found in the data (the optimal $\lambda$ in the DSGE-FAVAR is different from zero). Moreover, the optimal combination between the DSGE model and the statistical model based on a larger information set (the FAVAR) delivers a forecasting model (the DSGE-FAVAR) that dominates all alternatives.

The fact that the forecasting performance of the DSGE-FAVAR is the best among all alternatives, is somewhat reassuring against the worry that an artificially high value for the parameter $\lambda$ might be chosen by maximizing the marginal likelihood. In fact, such criterion puts a considerable weight in favour of parsimony of specification, therefore more richly parameterized models might be unduly penalized by the lambda-test when they are evaluated against very parsimoniously parameterized theoretical models.

Our comparative analysis of the DSGE-VAR and the DSGE-FAVAR reiterates the point made by Christiano(2007) on the importance of complementing the value of the optimal $\lambda$ with a cutoff function giving some weight to the difference between the number of free parameters in the unrestricted chosen statistical benchmark and in the DSGE model.

We conclude that the criticism of the Cowles Commission approach to model evaluation originally proposed by Spanos(1990) and centered on their lack of statistical identification might well apply to DSGE models and the recently proposed model evaluation method, based on the $D S G E-V A R(\lambda)$, is unlikely to detect the importance of such problem.

However, our application also shows that the adoption of a FAVAR as benchmark leaves unaltered the support of the data for the DSGE model and that a DSGE-FAVAR is the optimal forecasting model.

\section{References}

[1] Amisano, G., and Giannini, C. (1996). Topics in Structural VAR Econometrics. Springer-Verlag.

[2] An, Sungbae, and Frank Schorfheide (2006): "Bayesian Analysis of DSGE Models", Working Paper, 06-5, Federal Reserve Bank of Atlanta.

[3] Anderson, T.W. and H. Rubin (1949) "Estimation of the parameters of a single equation in a complete system of stochastic equations" Annals of Mathematical Statistics 20, 46-63.

[4] Bai, J. and S. Ng (2000), "Determining the number of factors in approximate factor models", Econometrica, 70.

[5] Basmann, R.L. (1960). "On finite sample distributions of generalized classical linear identifiability test statistic." Journal of the American Statistical Association 55. 650-659. 
[6] Bernanke, Ben S., and Jean Boivin (2003): "Monetary Policy in a DataRich Environment," Journal of Monetary Economics, L, 52-5464.

[7] Bernanke, Ben S., Jean Boivin and Piotr Eliasz (2005): " Measuring the Effects of Monetary Policy a Factor-Augmented Vector Autoregressive (FAVAR) Approach," The Quarterly Journal of Economics, MIT Press, vol. 120(1), pages 387-422, January.

[8] Boivin, Jean, and Marc P. Giannoni (2006):"DSGE Models in a DataRich Environment," NBER Working Papers 12772, National Bureau of Economic Research, Inc

[9] Canova, F. and L. Sala (2006) "Back to Square one: identification issues in DSGE models" , IGIER Working Paper 303, Università Bocconi

[10] Christiano, Lawrence J. (2007): "Comment on M.Del Negro, F.Schorfheide, F.Smets and R.Wouters "On the Fit of New-Keynesian Models"", mimeo.

[11] Christiano, L. J., Martin Eichenbaum, and Charles Evans (1998). 'Monetary Policy shocks: what have we learned and to what end?'. NBER working paper No. 6400

[12] Christiano, L. J., Martin Eichenbaum, and Charles Evans (2005): "Nominal Rigidities and the Dynamic effects of a Shock to Monetary Policy," Journal of Political Economy, 113, 1-45.

[13] Chudik, Alexander and M. Hashem Pesaran (2007) "Infinite Dimensional VARs and Factor Models",

http://www.econ.cam.ac.uk/faculty/pesaran/wp2007/PesaranChudikpaper19Nov07.pdf

[14] Clarida, Richard, Jordi Galì, and Mark Gertler (2000): "Monetary Policy Rules and Macroeconomics Stability: Evidence and some Theory," Quarterly Journal of Economics, 115, 147-180.

[15] Cogley t. and T.J. Sargent (2005) "Drifts and Volatilities: Monetary Policies and Outcomes in post WWII U.S.", Review of Economic Dynamics, 8 (2), 262-302

[16] Del Negro, Marco, and Frank Schorfheide (2004): " Priors from General equilibrium Models for VARs," International Economic Review, 45, 643673.

[17] Del Negro, Marco, and Frank Schorfheide (2006): "How Good is what You've Got? DSGE-VAR as a Toolkit for evaluating DSGE Models," Federal Reserve Bank of Atlanta Economic Review

[18] Del Negro, Marco, Frank Schorfheide, Frank Smets and Raf Wouters (2006): "On the Fit of New-Keynesisan Models," Journal of Business, Economics and Statistics, 25,2, 124-162.

[19] Engle R., Hendry D.F. and J.F. Richard (1983) "Exogeneity", Econometrica, 51, 277-302

[20] Engle R.F. and K.F. Kroner(1995) "Multivariate Simultaneous Generalized ARCH", Econometric Theory, 11, 122-150 
[21] Fernandez-Villaverde J., J. Rubio-Ramirez, T.J. Sargent and M.W. Watson (2007) "ABCs (and Ds) of understanding VARs", the American Economic Review, 97, 3,

[22] Fernandez-Villaverde J. and J.Rubio-Ramirez (2007a) "Estimating Macroeconomic Models: A Likelihood Approach, Review of Economic Studies, forthcoming

[23] Fernandez-Villaverde J. and J.Rubio-Ramirez (2007b) "How Structural are Structural Parameters?", in NBER Macroeconomics Annual, forthcoming

[24] Forni, M. and L. Reichlin (1996), "Dynamic common factors in large crosssections", Empirical Economics, 21, 27-42.

[25] Forni, M. and L. Reichlin (1998), "Let's get real: A dynamic factor analytical approach to disaggregated business cycle", Review of Economic Studies, 65, 453-474.

[26] Forni, M., Hallin, M., Lippi, M. and L. Reichlin (1999), "Reference cycles: The NBER methodology revisited", mimeo.

[27] Forni, M., Hallin, M., Lippi, M. and L. Reichlin (2000), "The generalized factor model: identification and estimation", The Review of Economic and Statistics,

[28] Gelfand A.E. and D.K. Dey(1994) "Bayesian Model Choice: Asymptotics and Exact Calculations," Journal of The Royal Statistical Society Series B 56:501-514

[29] Geweke, John (1999): "Using Simulation Methods for Bayesian Econometric Models: Inference, Development, and Communications," Econometrics Reviews, 18, 1-127.

[30] Giannone D., M.Lenza and L.Reichlin(2008), "Explaining the Great Moderation. It is not the Shocks", ECB Working Paper Series, 865

[31] Godfrey L.G.(1988) Misspecification Tests in Econometrics, Cambridge University Press

[32] Hamilton J.(1994) Time Series Analysis, Princeton University Press

[33] Hendry, D. F. (1995). Dynamic Econometrics. Oxford: Oxford University Press.

[34] Jarque C.M. and Bera A.K.(1980) "Efficient tests for normality, homoscedasticity and serial independence of regression residuals", Economic Letters, 6, 255-259

[35] Justiniano A. and G.Primiceri (2008) "The Time Varying volatility of Macroeconomic Fluctuations", The American Economic Review, forthcoming

[36] Lucas, R. E. Jr. (1976). 'Econometric Policy Evaluation: A Critique'. In K. Brunner and A. Meltzer (eds.) The Phillips curve and labor markets. Amsterdam: North-Holland. 
[37] Maddala (1988) Introduction to Econometrics, Mac Millan, New York, NY

[38] Primiceri G.(2005) "Time Varying Vector Autoregressions and Monetary Policy", The Review of Economic Studies, 72, 821-852

[39] Schorfheide, Frank (2000): "Loss Function-Based Evaluation of DSGE Models," Journal of Applied Econometrics, 15, S645-670.

[40] Ravenna F.(2007) "Vector Autoregressions and Reduced Form Representations of DSGE models", Journal of Monetary Economics, 54, 7, 20482064

[41] Sims, C. A. (1980). 'Macroeconomics and Reality'. Econometrica, 48: 1-48.

[42] Sims, C. A. (1992): "Interpreting the Macroeconomic Time Series facts: The Effects of Monetary Policy," European Economic Review, XXXVI, 975-1000.

[43] Sims, C. A. (1996): "Macroeconomics and Methodology", Journal of Economic Perspectives, 10, Winter 1996, 105-120.

[44] Sims, C. A. (2002): "Solving Linear Rational Expectations Models," Computational Economics, 20 (1-2), 1-20.

[45] Sims, C. A. and T. Zha (1998): "Bayesian Methods for Dynamic Multivariate Models," International Economic Review, 39, 949-968.

[46] Sims, C.A. and T.Zha (2006) "Were There Regime Switches in U.S. Monetary Policy?", The American Economic Review, 96(1), 54-81

[47] Smets, Frank, and Raf Wouters (2003): "An Estimated Stochastic Dynamic General Equilibrium Model of the Euro Area," Journal of the European Economic Association, 1, 1123-75.

[48] Spanos, Aris (1990): "The Simultaneous-Equations Model Revisited: Statistical Adequacy and Identification", Journal of Econometrics, 44, 87105.

[49] Stock, J.H. and M.W. Watson (1998), "Diffusion indexes", NBER WP 6702 .

[50] Stock, James, and Mark Watson (1999) "Forecasting Inflation", Journal of Monetary Economics, Vol. 44, no. 2

[51] Stock, James, and Mark Watson (2002): "Macroeconomic Forecasting Using Diffusion Indexes," Journal of Business Economics and Statistics, XX:II, 147-162.

[52] Theil, Henry, and Arthur S. Goldberg (1961): "On Pure and Mixed Estimation in Economics," International Economic Review, 2, 65-78.

[53] White H.(1980) "A heteroscedastic-consistent covariance matrix estimator and a direct test for heteroscedasticity", Econometrica, 48, 817-838.

[54] Woodford M.(2003) "Interest and Prices", Princeton University Press 


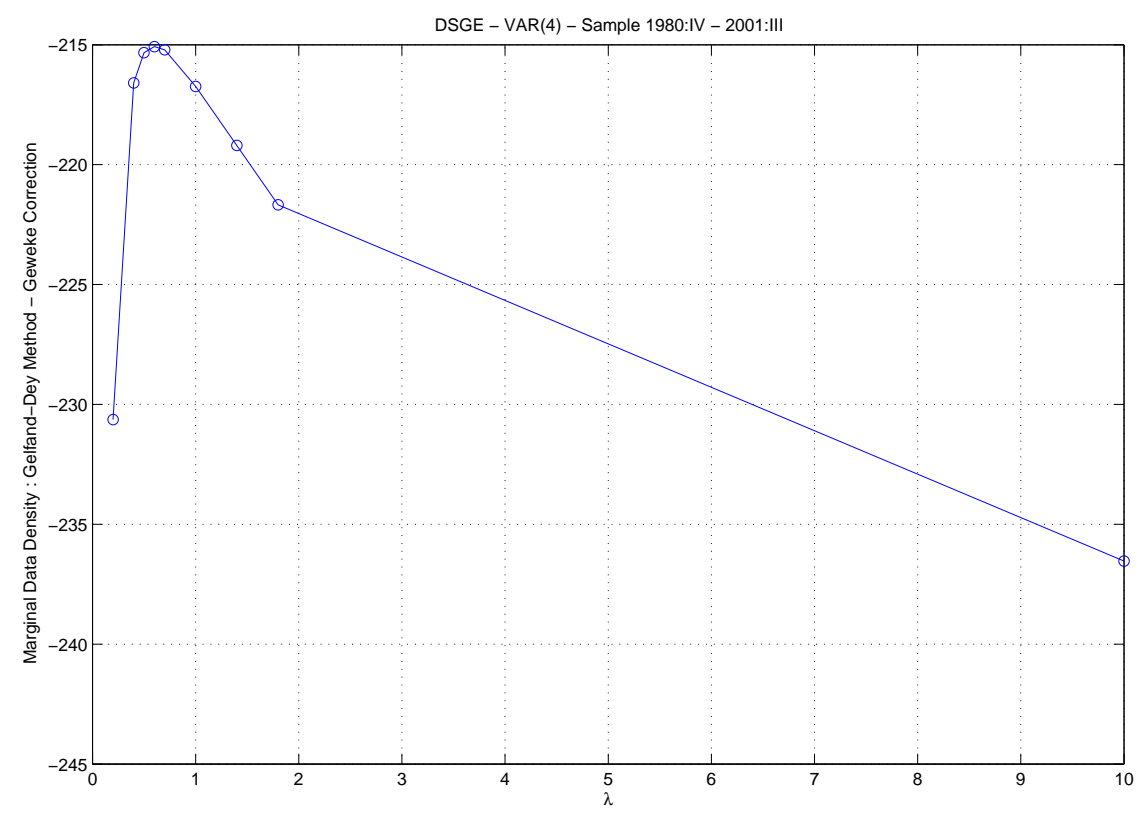

Figure 1: The optimal $\lambda$ in the DSGE-VAR 

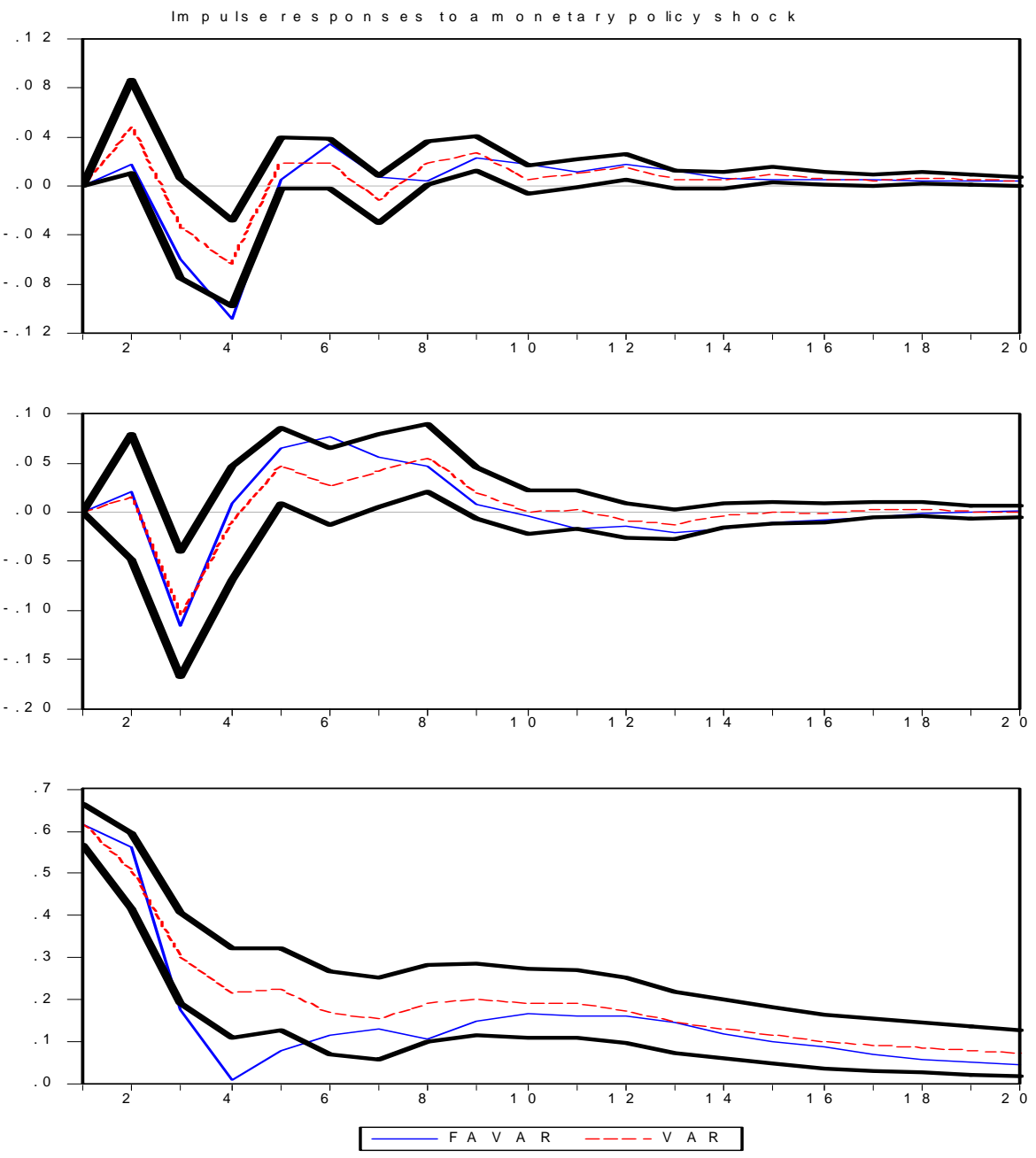

Figure 2:Responses of quarterly inflation, quarterly GDP growth and monetary policy rates to a monetary policy shock in the VAR and in the FAVAR(4) 


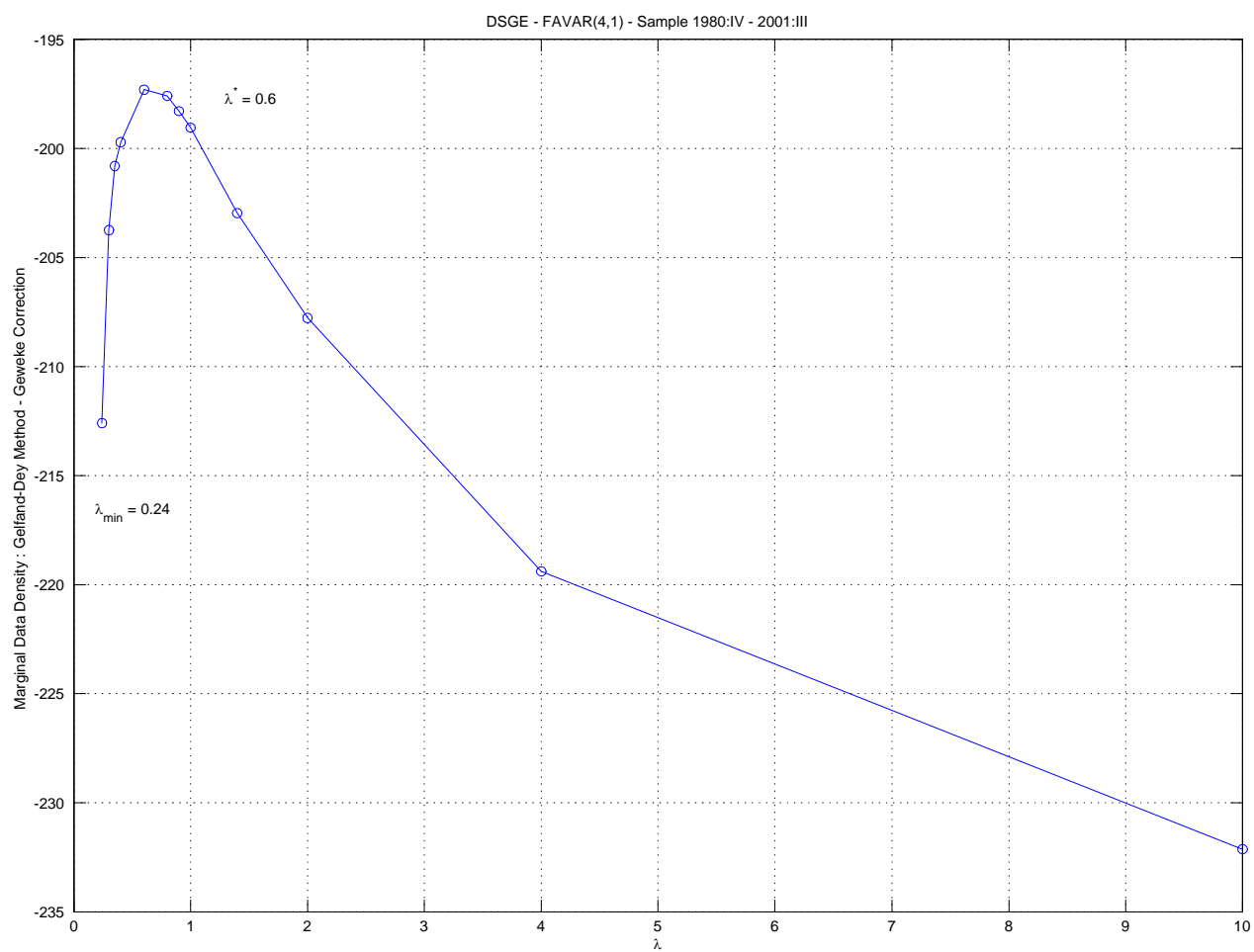

Figure 3: the optimal $\lambda$ in a DSGE-FAVAR

\section{Appendix A : The Sims Representation of our simple model}

Del Negro and Schorfheide (2004) consider the following model:

$$
\begin{aligned}
\tilde{x}_{t} & =E_{t} \tilde{x}_{t+1}-\frac{1}{\tau}\left(\tilde{R}_{t}-E_{t} \tilde{\pi}_{t+1}\right)+\left(1-\rho_{G}\right) \tilde{g}_{t}+\rho_{z} \frac{1}{\tau} \tilde{z}_{t} \\
\tilde{\pi}_{t} & =\beta E_{t} \tilde{\pi}_{t+1}+\kappa\left(\tilde{x}_{t}-\tilde{g}_{t}\right) \\
\tilde{R}_{t} & =\rho_{R} \tilde{R}_{t-1}+\left(1-\rho_{R}\right)\left(\psi_{1} \tilde{\pi}_{t}+\psi_{2} \tilde{x}_{t}\right)+\epsilon_{R, t} \\
\tilde{g}_{t} & =\rho_{g} \tilde{g}_{t-1}+\epsilon_{g, t} \\
\tilde{z}_{t} & =\rho_{z} \tilde{z}_{t-1}+\epsilon_{z, t}
\end{aligned}
$$


The first step towards solution is to cast the model in the form of :

$$
\Gamma_{0} \tilde{\mathbf{Z}}_{t}=\Gamma_{1} \tilde{\mathbf{Z}}_{t-1}+C+\Psi \epsilon_{t}+\Pi \eta_{t}
$$

The results is achieved as follows:

$$
\begin{aligned}
& \tilde{\mathbf{Z}}_{t}=\left[\begin{array}{c}
\widetilde{x_{t}} \\
\widetilde{\pi_{t}} \\
\widetilde{R_{t}} \\
\widetilde{R_{t}^{*}} \\
\widetilde{g_{t}} \\
\widetilde{z_{t}} \\
E_{t} \widetilde{x_{t+1}} \\
E_{t} \widetilde{\pi_{t+1}}
\end{array}\right] \quad \epsilon_{t}=\left[\begin{array}{c}
\epsilon_{t}^{R} \\
\epsilon_{t}^{G} \\
\epsilon_{t}^{Z}
\end{array}\right] \quad \eta_{t}=\left[\begin{array}{l}
\eta_{t}^{x}=x_{t}-E_{t-1}\left(x_{t}\right) \\
\eta_{t}^{\pi}=\pi_{t}-E_{t-1}\left(\pi_{t}\right)
\end{array}\right] \\
& \Gamma_{0}=\left[\begin{array}{cccccccc}
1 & 0 & \frac{1}{\tau} & 0 & -\left(1-\rho_{g}\right) & -\frac{\rho_{z}}{\tau} & -1 & -\frac{1}{\tau} \\
-\kappa & 1 & 0 & 0 & \kappa & 0 & 0 & -\beta \\
0 & 0 & 1 & -\left(1-\rho_{R}\right) & 0 & 0 & 0 & 0 \\
-\psi_{2} & -\psi_{1} & 0 & 1 & 0 & 0 & 0 & 0 \\
0 & 0 & 0 & 0 & 1 & 0 & 0 & 0 \\
0 & 0 & 0 & 0 & 0 & 1 & 0 & 0 \\
1 & 0 & 0 & 0 & 0 & 0 & 0 & 0 \\
0 & 1 & 0 & 0 & 0 & 0 & 0 & 0
\end{array}\right] \\
& \Gamma_{1}=\left[\begin{array}{cccccccc}
0 & 0 & 0 & 0 & 0 & 0 & 0 & 0 \\
0 & 0 & 0 & 0 & 0 & 0 & 0 & 0 \\
0 & 0 & \rho_{R} & 0 & 0 & 0 & 0 & 0 \\
0 & 0 & 0 & 0 & 0 & 0 & 0 & 0 \\
0 & 0 & 0 & 0 & \rho_{G} & 0 & 0 & 0 \\
0 & 0 & 0 & 0 & 0 & \rho_{Z} & 0 & 0 \\
0 & 0 & 0 & 0 & 0 & 0 & 1 & 0 \\
0 & 0 & 0 & 0 & 0 & 0 & 0 & 1
\end{array}\right] \\
& \Psi=\left[\begin{array}{lll}
0 & 0 & 0 \\
0 & 0 & 0 \\
1 & 0 & 0 \\
0 & 0 & 0 \\
0 & 1 & 0 \\
0 & 0 & 1 \\
0 & 0 & 0 \\
0 & 0 & 0
\end{array}\right] \quad \Pi=\left[\begin{array}{ll}
0 & 0 \\
0 & 0 \\
0 & 0 \\
0 & 0 \\
0 & 0 \\
0 & 0 \\
1 & 0 \\
0 & 1
\end{array}\right]
\end{aligned}
$$




\section{Appendix B : The data used to extract fac- tors}

We describe data used to extract factors in the format adopted by Stock and Watson(2002):series number, long description, short description, transformation code and slow code ( 0 . The transformation code are: 1 - no transformation; 2 - first difference; 3 - second difference; 4 - logarithm; 5 - first difference of logarithm and 6 - second difference of logarithm.

\begin{tabular}{|c|c|c|c|c|}
\hline Date & Long Description & Short Desc & Transf cod & SlowCod \\
\hline a0m052 & Personal income (AR, bil. chain $2000 \$)$ & $\mathrm{Pl}$ & 5 & 1 \\
\hline A0M051 & Personal income less transfer payments (AR, bil. chain $2000 \$$ ) & PI less transfer & 5 & 1 \\
\hline A0M224 & Real Consumption (AC) A0m224/gmdc & Consumption & 5 & 1 \\
\hline A0M057 & Manufacturing and trade sales (mil. Chain 1996 \$) & M\&T sales & 5 & 1 \\
\hline A0M059 & Sales of retail stores (mil. Chain $2000 \$$ ) & Retail sales & 5 & 1 \\
\hline IPS10 & INDUSTRIAL PRODUCTION INDEX - TOTAL INDEX & IP: total & 5 & 1 \\
\hline IPS11 & INDUSTRIAL PRODUCTION INDEX - PRODUCTS, TOTAL & IP: products & 5 & 1 \\
\hline IPS299 & INDUSTRIAL PRODUCTION INDEX - FINAL PRODUCTS & IP: final prod & 5 & 1 \\
\hline IPS12 & INDUSTRIAL PRODUCTION INDEX - CONSUMER GOODS & IP: cons gds & 5 & 1 \\
\hline IPS13 & INDUSTRIAL PRODUCTION INDEX - DURABLE CONSUMER GOODS & IP: cons dble & 5 & 1 \\
\hline IPS18 & INDUSTRIAL PRODUCTION INDEX - NONDURABLE CONSUMER GOOD & ilP:cons nondb| & 5 & 1 \\
\hline IPS25 & INDUSTRIAL PRODUCTION INDEX - BUSINESS EQUIPMENT & IP:bus eqpt & 5 & 1 \\
\hline IPS32 & INDUSTRIAL PRODUCTION INDEX - MATERIALS & IP: matls & 5 & 1 \\
\hline IPS34 & INDUSTRIAL PRODUCTION INDEX - DURABLE GOODS MATERIALS & IP: dble mats & 5 & 1 \\
\hline IPS38 & INDUSTRIAL PRODUCTION INDEX - NONDURABLE GOODS MATERIALS & IP:nondble mat & 5 & 1 \\
\hline IPS43 & INDUSTRIAL PRODUCTION INDEX - MANUFACTURING (SIC) & IP: $\mathrm{mfg}$ & 5 & 1 \\
\hline IPS307 & INDUSTRIAL PRODUCTION INDEX - RESIDENTIAL UTILITIES & IP: res util & 5 & 1 \\
\hline IPS306 & INDUSTRIAL PRODUCTION INDEX - FUELS & IP: fuels & 5 & 1 \\
\hline PMP & NAPM PRODUCTION INDEX (PERCENT) & NAPM prodn & 1 & 1 \\
\hline A0m082 & Capacity Utilization (Mfg) & Cap util & 2 & 1 \\
\hline LHEL & INDEX OF HELP-WANTED ADVERTISING IN NEWSPAPERS (1967=100;S & Help wanted ind & 2 & 1 \\
\hline LHELX & EMPLOYMENT: RATIO; HELP-WANTED ADS:NO. UNEMPLOYED CLF & Help wanted/en & 2 & 1 \\
\hline LHEM & CIVILIAN LABOR FORCE: EMPLOYED, TOTAL (THOUS.,SA) & Emp CPS total & 5 & 1 \\
\hline LHNAG & CIVILIAN LABOR FORCE: EMPLOYED, NONAGRIC.INDUSTRIES (THOUS & Emp CPS nona & 5 & 1 \\
\hline LHUR & UNEMPLOYMENT RATE: ALL WORKERS, 16 YEARS \& OVER $(\%, S A)$ & U: all & 2 & 1 \\
\hline LHU680 & UNEMPLOY.BY DURATION: AVERAGE(MEAN)DURATION IN WEEKS (SA) & U: mean duratid & 2 & 1 \\
\hline LHU5 & UNEMPLOY.BY DURATION: PERSONS UNEMPL.LESS THAN 5 WKS (TH & $U<5$ wks & 5 & 1 \\
\hline LHU14 & UNEMPLOY.BY DURATION: PERSONS UNEMPL. 5 TO 14 WKS (THOUS., & U 5-14 wks & 5 & 1 \\
\hline LHU15 & UNEMPLOY.BY DURATION: PERSONS UNEMPL.15 WKS + (THOUS.,SA) & U $15+$ wks & 5 & 1 \\
\hline LHU26 & UNEMPLOY.BY DURATION: PERSONS UNEMPL.15 TO 26 WKS (THOUS. & U 15-26 wks & 5 & 1 \\
\hline LHU27 & UNEMPLOY.BY DURATION: PERSONS UNEMPL.27 WKS + (THOUS,SA) & U $27+$ wks & 5 & 1 \\
\hline A0M005 & Average weekly initial claims, unemploy. insurance (thous.) & Ul claims & 5 & 1 \\
\hline CESOO2 & EMPLOYEES ON NONFARM PAYROLLS - TOTAL PRIVATE & Emp: total & 5 & 1 \\
\hline CESO03 & EMPLOYEES ON NONFARM PAYROLLS - GOODS-PRODUCING & Emp: gds prod & 5 & 1 \\
\hline CESO06 & EMPLOYEES ON NONFARM PAYROLLS - MINING & Emp: mining & 5 & 1 \\
\hline CES011 & EMPLOYEES ON NONFARM PAYROLLS - CONSTRUCTION & Emp: const & 5 & 1 \\
\hline CESO15 & EMPLOYEES ON NONFARM PAYROLLS - MANUFACTURING & Emp: $\mathrm{mfg}$ & 5 & 1 \\
\hline CES017 & EMPLOYEES ON NONFARM PAYROLLS - DURABLE GOODS & Emp: dble gds & 5 & 1 \\
\hline CESO33 & EMPLOYEES ON NONFARM PAYROLLS - NONDURABLE GOODS & Emp: nondbles & 5 & 1 \\
\hline
\end{tabular}


CES046 EMMPLOYEES ON NONFARM PAYROLLS - SERVICE-PROVIDING CESO48 EMPLOYEES ON NONFARM PAYROLLS - TRADE, TRANSPORTATION, A Emp: TTU CES049 EMPLOYEES ON NONFARM PAYROLLS - WHOLESALE TRADE CES053 EMPLOYEES ON NONFARM PAYROLLS - RETAIL TRADE CES088 EMPLOYEES ON NONFARM PAYROLLS - FINANCIAL ACTIVITIES CES140 EMPLOYEES ON NONFARM PAYROLLS - GOVERNMENT A0M048 Employee hours in nonag. establishments (AR, bil. hours) CES151 AVERAGE WEEKLY HOURS OF PRODUCTION OR NONSUPERVISORY CES155 AVERAGE WEEKLY HOURS OF PRODUCTION OR NONSUPERVISORY aom001 Average weekly hours, mfg. (hours) PMEMP NAPM EMPLOYMENT INDEX (PERCENT)

HSFR HOUSING STARTS:NONFARM(1947-58);TOTAL FARM\&NONFARM(1959-) HSNE HOUSING STARTS:NORTHEAST (THOUS.U.)S.A. HSMW HOUSING STARTS:MIDWEST(THOUS.U.)S.A. HSSOU HOUSING STARTS:SOUTH (THOUS.U.)S.A. HSWST HOUSING STARTS:WEST (THOUS.U.)S.A. HOUSING AUTHORIZED: TOTAL NEW PRIV HStarts: Total HStarts: NE HStarts: MW HStarts: South HStarts: West

HSBNE HOUSES AUTHORIZED BY BUILD. PERMITS:NORTHEAST(THOUUUS., B BP. tota HSBMW HOUSES AUTHORIZED BY BUILD. PERMITS:MIDWEST(THOU.U.)S.A. HSBSOL HOUSES AUTHORIZED BY BUILD. PERMITS:SOUTH(THOU.U.)S.A. HSBWS HOUSES AUTHORIZED BY BUILD. PERMITS:WEST(THOU.U.)S.A. PURCHASING MANAGERS' INDEX (SA)

PMNO NAPM NEW ORDERS INDEX (PERCENT)

PMDEL NAPM VENDOR DELIVERIES INDEX (PERCENT)

PMNV NAPM INVENTORIES INDEX (PERCENT)

A0M008 Mfrs' new orders, consumer goods and materials (bil. chain $1982 \$$ )

A0M007 Mfrs' new orders, durable goods industries (bil. chain 2000 \$)

A0M027 Mfrs' new orders, nondefense capital goods (mil. chain 1982 \$)

A1M092 Mfrs' unfilled orders, durable goods indus. (bil. chain 2000 \$)

A0M070 Manufacturing and trade inventories (bil. chain 2000 \$)

A0M077 Ratio, mfg. and trade inventories to sales (based on chain 2000 \$)

FM1 MONEY STOCK: M1(CURR,TRAV.CKS,DEM DEP,OTHER CK'ABLE DEP)(BIL\$,SA)

MONEY STOCK:M2(M1+O'NITE RPS,EURO\$,G/P\&B/D MMMFS\&SAV\&SM TIME DEP(B MONEY STOCK: M3(M2+LG TIME DEP,TERM RP'S\&INST ONLY MMMFS)(BIL\$,SA)

FM2DQ MONEY SUPPLY - M2 IN 1996 DOLLARS (BCI)

FMFBA MONETARY BASE, ADJ FOR RESERVE REQUIREMENT CHANGES(MIL\$,SA)

FMRRA DEPOSITORY INST RESERVES:TOTAL,ADJ FOR RESERVE REQ CHGS(MIL\$,SA)

FMRNBA DEPOSITORY INST RESERVES:NONBORROWED,ADJ RES REQ CHGS(MIL\$,SA)

FCLNQ COMMERCIAL \& INDUSTRIAL LOANS OUSTANDING IN 1996 DOLLARS (BCI)

FCLBMC WKLY RP LG COM'L BANKS:NET CHANGE COM'L \& INDUS LOANS(BIL\$,SAAR)

CCINRV CONSUMER CREDIT OUTSTANDING - NONREVOLVING(G19)

BP: NE
BP: MW
BP: South
BP: West
PMI
NAPM new ord
NAPM vendor
NAPM Invent
Orders: cons gds
Orders: dble gds
Orders: cap gds
Unf orders: dble
M\&T invent
M\&T invent/sales
M1
M2
M3
M2 (real)
MB
Reserves tot
Reserves nonbor
C\&l loans
C\&l loans
Cons credit




\begin{tabular}{|c|c|c|c|}
\hline A0M095 & Ratio, consumer installment credit to personal income (pct.) & |lnst cred/PI & 2 \\
\hline FSPCOM & S\&P'S COMMON STOCK PRICE INDEX: COMPOSITE (1941-43=10) & S\&P 500 & 5 \\
\hline FSPIN & S\&P'S COMMON STOCK PRICE INDEX: INDUSTRIALS (1941-43=10) & S\&P: indust & 5 \\
\hline FSDXP & S\&P'S COMPOSITE COMMON STOCK: DIVIDEND YIELD (\% PER ANNUM) & S\&P div yield & 2 \\
\hline FSPXE & S\&P'S COMPOSITE COMMON STOCK: PRICE-EARNINGS RATIO (\%,NSA) & S\&P PE ratio & 5 \\
\hline FYFF & |INTEREST RATE: FEDERAL FUNDS (EFFECTIVE) (\% PER ANNUM,NSA) & FedFunds & 2 \\
\hline CP90 & Cmmercial Paper Rate (AC) & Commpaper & 2 \\
\hline FYGM3 & INTEREST RATE: U.S.TREASURY BILLS,SEC MKT,3-MO.(\% PER ANN,NSA) & 3 mo T-bill & 2 \\
\hline FYGM6 & INTEREST RATE: U.S.TREASURY BILLS,SEC MKT,6-MO.(\% PER ANN,NSA) & 6 mo T-bill & 2 \\
\hline FYGT1 & INTEREST RATE: U.S.TREASURY CONST MATURITIES,1-YR.(\% PER ANN,NSA) & 1 yr T-bond & 2 \\
\hline FYGT5 & INTEREST RATE: U.S.TREASURY CONST MATURITIES,5-YR.(\% PER ANN,NSA) & 5 yr T-bond & 2 \\
\hline FYGT10 & INTEREST RATE: U.S.TREASURY CONST MATURITIES,10-YR.(\% PER ANN,NSA) & $10 \mathrm{yr}$ T-bond & 2 \\
\hline FYAAAC & BOND YIELD: MOODY'S AAA CORPORATE (\% PER ANNUM) & Aaabond & \\
\hline FYBAAC & BOND YIELD: MOODY'S BAA CORPORATE (\% PER ANNUM) & Baa bond & -1 \\
\hline $\operatorname{scp} 90$ & cp90-fyff & CP-FF spread & 1 \\
\hline sfygm3 & fygm3-fyff & 3 mo-FF spread & 1 \\
\hline sFYGM6 & fygm6-fyff & 6 mo-FF spread & 1 \\
\hline SFYGT1 & fygt1-fyff & 1 yr-FF spread & 1 \\
\hline SFYGT5 & fygt5-fyff & 5 yr-FFspread & 1 \\
\hline sFYGT10 & fygt10-fyff & 10yr-FF spread & 1 \\
\hline SFYAAAC & fyaaac-fyff & Aaa-FF spread & 1 \\
\hline SFYBAAC & fybaac-fyff & Baa-FF spread & 1 \\
\hline EXRUS & UNITED STATES;EFFECTIVE EXCHANGE RATE(MERM)(INDEX NO.) & Ex rate: avg & 5 \\
\hline EXRSW & FOREIGN EXCHANGE RATE: SWITZERLAND (SWISS FRANC PER U.S.\$) & Ex rate: Switz & 5 \\
\hline EXRJAN & FOREIGN EXCHANGE RATE: JAPAN (YEN PER U.S.\$) & Ex rate: Japan & \\
\hline EXRUK & FOREIGN EXCHANGE RATE: UNITED KINGDOM (CENTS PER POUND) & Ex rate: UK & \\
\hline EXRCAN & FOREIGN EXCHANGE RATE: CANADA (CANADIAN \$ PER U.S.\$) & EX rate: Canada & 4 \\
\hline PWFSA & PRODUCER PRICE INDEX: FINISHED GOODS $(82=100, S A)$ & PPI: fin gds & 6 \\
\hline PWFCSA & PRODUCER PRICE INDEX:FINISHED CONSUMER GOODS $(82=100, S A)$ & PPI: cons gds & 6 \\
\hline PWIMSA & PRODUCER PRICE INDEX:INTERMED MAT.SUPPLIES \& COMPONENTS(82=100,SA) & PPI: int mat'ls & 6 \\
\hline PWCMSA & PRODUCER PRICE INDEX:CRUDE MATERIALS $(82=100, S A)$ & PPI: crude mat'ls & 6 \\
\hline PSCCOM & SPOT MARKET PRICE INDEX:BLS \& CRB: ALL COMMODITIES(1967=100) & Commod: spot pri & 6 \\
\hline PSM99Q & INDEX OF SENSITIVE MATERIALS PRICES $(1990=100)(B C I-99 A)$ & Sens mat'ls price & 6 \\
\hline PMCP & NAPM COMMODITY PRICES INDEX (PERCENT) & NAPM com price & 1 \\
\hline PUNEW & CPI-U: ALL ITEMS (82-84=100,SA) & CPI-U: all & 6 \\
\hline PU83 & CPI-U: APPAREL \& UPKEEP (82-84=100,SA) & CPI-U: apparel & 1 \\
\hline PU84 & CPI-U: TRANSPORTATION (82-84=100,SA) & CPI-U: transp & 6 \\
\hline PU85 & CPI-U: MEDICAL CARE $(82-84=100, S A)$ & CPI-U: medical & 6 \\
\hline PUC & CPI-U: COMMODITIES (82-84=100,SA) & CPI-U: comm. & 6 \\
\hline PUCD & CPI-U: DURABLES $(82-84=100, S A)$ & CPI-U: dbles & 6 \\
\hline PUS & CPI-U: SERVICES $(82-84=100, S A)$ & CPI-U: services & 6 \\
\hline PUXF & CPI-U: ALL ITEMS LESS FOOD (82-84=100,SA) & CPI-U: ex food & 6 \\
\hline PUXHS & CPI-U: ALL ITEMS LESS SHELTER $(82-84=100, S A)$ & CPI-U: ex shelter & 6 \\
\hline PUXM & CPI-U: ALL ITEMS LESS MEDICAL CARE $(82-84=100, S A)$ & CPI-U: ex med & 6 \\
\hline GMDC & PCE,IMPL PR DEFL:PCE (1987=100) & PCE defl & 6 \\
\hline GMDCD & PCE,IMPL PR DEFL:PCE; DURABLES (1987=100) & PCE defl: dlbes & 6 \\
\hline GMDCN & PCE,IMPL PR DEFL:PCE; NONDURABLES $(1996=100)$ & PCE defl: nondble & 6 \\
\hline GMDCS & PCE,IMPL PR DEFL:PCE; SERVICES (1987=100) & PCE defl: services & 6 \\
\hline CES275 & AVERAGE HOURLY EARNINGS OF PRODUCTION OR NONSUPERVISORY WORKER & AHE: goods & 6 \\
\hline CES277 & AVERAGE HOURLY EARNINGS OF PRODUCTION OR NONSUPERVISORY WORKER & AHE: const & 6 \\
\hline CES278 & AVERAGE HOURLY EARNINGS OF PRODUCTION OR NONSUPERVISORY WORKER & AHE: $\mathrm{mfg}$ & 6 \\
\hline
\end{tabular}




\section{Appendix C: How to generate draws from the posterior distribution of $\left(\Phi, \Sigma_{u}, \theta\right)$}

Here we provide the full derivation of the results reported in Section 3 on the DS approach to obtain draws from the posterior distribution of $\left(\Phi, \Sigma_{u}, \theta\right)$. The analysis will be conditional to a value for $\lambda$ which establishes the relevance of the information between the VAR and DSGE in order to estimate the structural parameter $\theta$. We can think of $\lambda$ as generating a particular model which can support, with a certain degree, the observed data: the marginal data density represents such a measure of goodness and it would help us to discriminate among different models (i.e. different $\lambda$ ).

This appendix describes i) how to compute moments from DSGE models, ii) how to compute a proper prior distribution given such a set of moments conditions, iii) how to derive the marginal data density in case of conjugate prior, iv)

\subsection{The Bayesian Approach}

We follow the Bayesian approach to draw all the relevant inference for the problem at hand. We consider as a good approximation for the vector of observables, $Y_{t}=\left(\Delta \ln y_{t}, \Delta \ln p_{t}, R_{t}\right)^{\prime}$, an unrestricted Gaussian VAR(p) model for the data.

Together with the likelihood function for the $\operatorname{VAR}(\mathrm{p})$ we have to specify a prior distribution for the VAR coefficients. According to Theil and Goldberg(1961) and following the application by Sims (1996), we can recover a prior distribution by using a set of dummy observations. Such a procedure could be seen as a set of restrictions on the $\operatorname{VAR}(\mathrm{p})$ coefficients as well. A novelty of the DS approach is to use the DSGE model to derive artificial data, $(\tilde{Y}, \tilde{X})$, which can be used to set up the prior.

The VAR model for the data is

$$
Y_{t}=\Phi X_{t}+E_{t}
$$

where $X_{t}=\left[\iota, Y_{t-1}^{\prime}, \ldots, Y_{t-p}^{\prime}\right]^{\prime}$ is a vector of dimension $k \times 1, k=m p+1$, which concatenates the constant and $p$ lags of $Y_{t}$, and $\Phi=\left[\Phi_{0}\left|\Phi_{1}\right| \ldots \Phi_{p}\right]$.

The DSGE model can be described by the following state-space representation

$$
\begin{aligned}
& \tilde{Y}_{t}=\Lambda_{0}(\theta)+\Lambda_{1}(\theta) \tilde{Z}_{t}+V_{t}, \\
& \tilde{Z}_{t}=T(\theta) \tilde{Z}_{t-1}+R(\theta) U_{t},
\end{aligned}
$$

which groups the policy function from the $\underset{\tilde{Z}}{\mathrm{RE}}$ equilibrium and the mapping between observables, $\tilde{Y}_{t}$, and simulated data, $\tilde{Z}_{t}$. The vector $\tilde{Y}_{t}$ can be computed by simulation methods with respect to (34) and (35) or analytically since the DSGE model is stationary. 
Given the pair of simulated data $\left(\tilde{Y}_{t}, \tilde{X}_{t}\right)^{14}$ we can write a similar specification as in (33)

$$
\tilde{Y}_{t}=\Phi \tilde{X}_{t}+E_{t}
$$

that indirectly imposes restrictions on $\Phi$ driven from the theoretical model; to derive the DSGE-based prior we will construct the likelihood function of the process in (36).

\subsection{Compute DSGE Moments}

Given the state-space representation in (34) and (35), the unconditional variance for $\tilde{Y}_{t}$ and $\tilde{Z}_{t}$ are

$$
\begin{aligned}
& \Sigma_{z, z}=T \Sigma_{z, z} T^{\prime}+R \Sigma_{u, u} R^{\prime} \\
& \Sigma_{y, y}=\Lambda_{0} \Lambda_{0}^{\prime}+\Lambda_{1} \Sigma_{z, z} \Lambda_{1}^{\prime}+\Sigma_{v, v}+\Lambda_{1} R \Sigma_{u, v}+\Sigma_{u, v}^{\prime} R^{\prime} \Lambda_{1}^{\prime}
\end{aligned}
$$

while the unconditional autocorrelation of order $k$ for $\tilde{Y}_{t}$ reads

$$
\begin{aligned}
& \Sigma_{z, z}(k)=T^{k} \Sigma_{z, z}(k-1) \\
& \Sigma_{y, y}(k)=\Lambda_{0} \Lambda_{0}^{\prime}+\Lambda_{1} \Sigma_{z, z}(k) \Lambda_{1}^{\prime}+\Lambda_{1}\left(T^{k}\right) R \Sigma_{u, v} .
\end{aligned}
$$

These high-order second moments matrices will be necessary to construct $\Sigma_{x, x}$ which is a function of the lags of $\tilde{Y}_{t}$. Here we have omitted the dependence over $\theta$.

\subsection{Getting a Proper Prior Distribution out of the DSGE model: $\pi_{1}$}

The likelihood function for the artificial data reads

$\mathcal{L}\left(\tilde{Y} ; \Phi, \Sigma_{e}\right)=(2 \pi)^{-m T / 2}\left|\Sigma_{e}\right|^{-T / 2} \exp \left(-\frac{1}{2} \operatorname{tr}\left(\left((\Phi-\tilde{\Phi})\left(\tilde{X}^{\prime} \tilde{X}\right)(\Phi-\tilde{\Phi})+\tilde{S}\right) \Sigma_{e}^{-1}\right)\right)$,

where the sufficient statistics are,

$$
\begin{aligned}
\tilde{\Phi} & =\left(\tilde{X}^{\prime} \tilde{X}\right)^{-1} \tilde{X}^{\prime} \tilde{Y} \\
\tilde{S} & =\tilde{Y}^{\prime} \tilde{Y}-\tilde{Y}^{\prime} \tilde{X}\left(\tilde{X}^{\prime} \tilde{X}\right)^{-1} \tilde{X}^{\prime} \tilde{Y}
\end{aligned}
$$

which can be also specified in terms of population moments

$$
\begin{aligned}
\tilde{\Phi} & =\Sigma_{x, x}^{-1} \Sigma_{x, y} \\
\tilde{S} & =\Sigma_{y, y}-\Sigma_{x, y}^{\prime} \Sigma_{x, x}^{-1} \Sigma_{x, y}
\end{aligned}
$$

\footnotetext{
${ }^{14} \tilde{X}_{t}$ collects lags of $\tilde{Y}_{t}$.
} 
where, for instance, $\Sigma_{x, y}=E\left(\tilde{X}_{t} \tilde{Y}_{t}\right)$.

We thus use a flat prior to construct a proper distribution based on the DSGE model: the Jeffreys prior for the multivariate case reads

$$
\pi_{0}=\left|\Sigma_{e}\right|^{-\frac{m+1}{2}} .
$$

By combining (41) and (46) we get the kernel of the distribution

$$
\pi_{1} \propto \mathcal{L}\left(\tilde{Y} \mid \Phi, \Sigma_{e}\right) \times \pi_{0}
$$

and by integrating with respect to $\left(\Phi, \Sigma_{e}\right)$ we derive the constant of integration

$$
P_{\tilde{Y}}(\tilde{Y} \mid \theta)=(2 \pi)^{-m \tilde{v} / 2} \times|\tilde{S}|^{-\frac{\tilde{v}}{2}} \times|\tilde{H}|^{-\frac{m}{2}} \times\left[2^{m \tilde{v} / 2} \times \pi^{m(m-1) / 4} \times \Gamma_{m}(\tilde{v})\right],
$$

which is needed to have the DSGE-based prior distribution

$$
\begin{aligned}
\pi_{1}\left(\Phi, \Sigma_{e} \mid \tilde{Y}, \theta\right)= & \frac{\mathcal{L}\left(\tilde{Y} \mid \Phi, \Sigma_{e}, \theta\right) \times \pi_{0}}{P_{\tilde{Y}}(\tilde{Y} \mid \theta)} \\
= & \frac{(2 \pi)^{-m T^{*} / 2}}{(2 \pi)^{-m \tilde{v} / 2}} \times \frac{|\tilde{S}|^{\tilde{v} / 2} \times|\tilde{H}|^{m / 2} \times\left|\Sigma_{e}\right|^{-\left(T^{*}+m+1\right) / 2}}{2^{m \tilde{v} / 2} \times \pi^{m(m-1) / 4} \times \Gamma_{m}(\tilde{v})} \times \\
& \exp \left[-\frac{1}{2} \operatorname{tr}\left(\tilde{S} \Sigma_{e}^{-1}\right)\right] \times \exp \left[-\frac{1}{2} \operatorname{tr}\left((\Phi-\tilde{\Phi})^{\prime}\left(\Sigma_{x, x}\right)(\Phi-\tilde{\Phi}) \Sigma_{e}^{-1}\right)\right]
\end{aligned}
$$

given $\Sigma_{x, x}$ non-singular and $\tilde{v} \equiv \tilde{T}-k>k+m$.

Hence, $\pi_{1}\left(\Phi, \Sigma_{e} \mid \tilde{Y}, \theta\right)$ is distribution from the Normal $\mathcal{N}\left(\tilde{\Phi}, \Sigma_{e} \otimes H^{-1}\right)$, Inverse-Wishart $\mathcal{I} \mathcal{W}(\tilde{S}, \tilde{v})$ family.

\subsection{The Marginal Data Density given: $P(Y \mid \theta)$}

With a proper prior at hand, $\pi_{1}$, we can now combine data and model-based information to fully specify the posterior conditional on the structural parameter $\theta$. By combining the likelihood and the conjugate prior, we get the posterior kernel

$$
P_{\Phi}\left(\Phi, \Sigma_{e} \mid Y, \theta\right) \propto \mathcal{L}\left(Y \mid \Phi, \Sigma_{e}\right) \times \pi_{1}\left(\Phi, \Sigma_{e} \mid \tilde{Y}, \theta\right),
$$


which can be integrated to obtain the marginal data density ${ }^{15}$

$$
P_{Y}(Y \mid \theta)=(2 \pi)^{-T m / 2} \times \frac{|\tilde{S}|^{\tilde{v} / 2}}{|\bar{S}|^{\bar{v} / 2}} \frac{|\tilde{H}|^{m / 2}}{|\bar{H}|^{m / 2}} \times \frac{\Gamma_{m}(\bar{v})}{\Gamma_{m}(\tilde{v})} \times 2^{m(\hat{v}+k) / 2}
$$

The proper posterior reads

$$
\begin{aligned}
P_{\Phi}\left(\Phi, \Sigma_{e} \mid Y, \theta\right)= & (2 \pi)^{-m k / 2} \times\left|\Sigma_{e}\right|^{-k / 2} \times \exp \left[-\frac{1}{2} \operatorname{tr}\left((\Phi-\bar{\Phi})^{\prime} \bar{H}(\Phi-\bar{\Phi}) \Sigma_{e}^{-1}\right)\right] \cdots \\
& \times \frac{|\bar{S}|^{\bar{v} / 2}|\bar{H}|^{m / 2} \times\left|\Sigma_{e}\right|^{-\left(\hat{v}+T^{*}+m+1\right) / 2}}{2^{m \bar{v} / 2} \times \pi^{m(m-1) / 4} \Gamma_{m}(\bar{v})} \times \exp \left[-\frac{1}{2} \operatorname{tr}\left(\bar{S} \Sigma_{e}^{-1}\right)\right] \quad(52)
\end{aligned}
$$

or equivalently

$$
\begin{aligned}
p\left(\Phi \mid \Sigma_{e} ; Y, X\right) & =N\left(\bar{\Phi}, \Sigma_{e} \otimes \bar{H}^{-1}\right) \\
p\left(\Sigma_{e} \mid Y, X\right) & =I W(\bar{S}, \bar{v})
\end{aligned}
$$

where the posterior estimates are as follows

- $\bar{H}=X^{\prime} X+\tilde{T} \Sigma_{x, x}$

- $\bar{\Phi}=\bar{H}^{-1}\left(X^{\prime} Y+\tilde{T} \Sigma_{x, y}\right)$

- $Q=\hat{\Phi}^{\prime} \hat{H} \hat{\Phi}+\tilde{\Phi}^{\prime} \tilde{H} \tilde{\Phi}-\bar{\Phi}^{\prime} \bar{H} \bar{\Phi}$

- $\bar{S}=\hat{S}+\tilde{S}+Q$

- $\bar{\Sigma}_{e}=\frac{\bar{S}}{\bar{v}}$

\subsection{Metropolis-Hasting Algorithm}

We have obtained the posterior distribution of the VAR coefficients given the structural parameters

$$
P(\Phi, \Sigma, \theta \mid Y)=P_{\Phi}(\Phi, \Sigma \mid Y, \theta) \times P_{\theta}(\theta \mid Y) .
$$

We also need to derive the posterior distribution with respect to $\theta$. We use the fact that

$$
P_{\theta}(\theta \mid Y) \propto \mathbb{K}_{\theta}(\theta \mid Y)=P_{Y}(Y \mid \theta) \times \pi_{2}(\theta)
$$

\footnotetext{
${ }^{15}$ where

$$
\begin{aligned}
\tilde{H} & =\left(\tilde{X}^{\prime} \tilde{X}\right) \\
\bar{v} & =T+\tilde{T}-k
\end{aligned}
$$
}


where $P_{Y}(Y \mid \theta)$ has been computed above and $\pi_{2}(\theta)$ is a set of independent prior distributions over each element of the vector of parameters $\theta ; \mathbb{K}_{\theta}(\theta \mid Y)$ is the kernel of the posterior. By combining the likelihood and the prior we don't have a closed form solution. We thus need to simulate draws out of the posterior distribution which is unknown. We follow Schorfheide (2000) and DS and we implement a Gaussian random walk Metropolis-Hasting algorithm to generate from $P_{\theta}(\theta \mid Y)$. We set as a scale factor the inverse of the Hessian matrix, $\Sigma_{H}(\theta)$, with respect to $\mathbb{K}_{\theta}(\theta \mid Y)$ evaluated at the mode, $\theta^{*}$. For each candidate draw, $\tilde{\theta}$,

$$
\tilde{\theta}=\theta_{s-1}+\left(\Sigma_{H}\left(\theta^{*}\right)\right)^{-1 / 2} N(0, I),
$$

we construct an acceptance probability threshold

$$
\alpha\left(\tilde{\theta}, \theta_{s-1}\right)=\min \left(1, \frac{\mathbb{K}_{\theta}(\tilde{\theta} \mid Y)}{\mathbb{K}_{\theta}\left(\theta_{s-1} \mid Y\right)}\right) .
$$

If $\alpha\left(\tilde{\theta}, \theta_{s-1}\right)$ is higher than a certain probability (varying for each draw) we accept the draw as coming from the posterior distribution $P_{\theta}(\theta \mid Y)$ and update the Markov chain $\theta_{s}=\tilde{\theta}$, otherwise we discard $\tilde{\theta}$ and draw another candidate from (57).

In doing so and by controlling for convergence of the chain, we are able to draw from the posterior distribution of $\theta$. Given the full set of draws, we can thus make inference on any function of the parameters.

\subsection{Gelfand-Dey Method for $P(Y)$}

We compute the marginal data density which consists of integrating out parameters from the posterior distribution to evaluate the set of models: they basically differ from each other from the weight implied by the parameter $\lambda$. However, in this case the functional form of the posterior, $P_{\theta}(\theta \mid Y)$, is not known and therefore we have to rely on simulation methods. To compute $P(Y)$ we use the Gelfand and Dey (1994) method with the correction suggested by Geweke (1999) to avoid problems in the tails of $P(Y)$ which, given the way it is computed, could be not finite.

Once we have a measure of the marginal data density for each model which, in our setup, depends on the choice of $\lambda$, we can then compare different models. The idea of comparing different models based on $\lambda$ clarifies the contribution of the information from the DSGE model in shaping inference. If the maximal of $P(Y)$ is attained for values of $\lambda$ close to zero, the DSGE model is not strongly supported by the data. 


\subsection{A FAVAR Analysis of the Simple DSGE Model}

In this case the benchmark specification for the unrestricted dynamics of the variables included in the theoretical model becomes the following:

$$
Y_{t}=B_{0} X_{t}+B_{1} F_{t}+E_{t}
$$

where $\mathbf{Y}_{t}=\left(\Delta \ln x_{t}, \Delta \ln P_{t}, \ln R_{t}\right), X_{t}=\left[1, \mathbf{Y}_{t-1}, \ldots \mathbf{Y}_{t-p}\right], F_{t}=\left[f_{t}^{\prime}, f_{t-1}^{\prime}, \ldots f_{t-q}^{\prime}\right]^{\prime}$ groups $q$ lags of the three factors $f_{t}=\left[f_{1, t}, f_{2, t}, f_{3, t}\right]^{\prime}$ extracted and interpreted as in Bernanke, Boivin and Eliasz $(2005), E_{t}$ is the three-variate vector of innovations. System (59) can be re-written in a more compact form as follows:

$$
Y_{t}=B W_{t}+E_{t}
$$

where $B=\left[B_{0}, B_{1}\right]$ is of dimension $m \times(1+m p+r q)$ and $W_{t}=\left[X_{t}^{\prime}, F_{t}^{\prime}\right]^{\prime}$.

\subsubsection{Prior distribution}

The full prior on the coefficients in (60) is derived by recalling the moments from the DSGE model as we did in Section 3 and by working out a prior for the factors coefficients which is centered at zero with a variance-covariance matrix set by the second moments matrix of the factors. Given that factors do not enter in the DSGE model, we can draw dummy observations from the theoretical model for the endogenous variables, $\left(\tilde{Y}_{t}, \tilde{X}_{t}\right),{ }^{16}$ without considering the effect from $\tilde{F}_{t}$. At the same time we can derive dummy observations to set the prior on the coefficients of the factors, $\tilde{F}_{t}$, by using a training sample on the full FAVAR. The set of dummy observations $\left(\tilde{Y}_{t}, \tilde{X}_{t}, \tilde{F}_{t}\right)$ can be used to derive the full prior distribution over the coefficients which reads

$$
\left[\begin{array}{c}
B_{0} \\
B_{1}
\end{array}\right] \mid \Sigma_{e} \sim N\left(\left[\begin{array}{c}
\tilde{B}_{0} \\
0
\end{array}\right], \Sigma_{e} \otimes\left[\begin{array}{cc}
\left(\tilde{X}_{t} \tilde{X}_{t}^{\prime}\right)^{-1} & 0 \\
0 & \left(\tilde{F}_{t} \tilde{F}_{t}^{\prime}\right)^{-1}
\end{array}\right]\right)
$$

where $\tilde{B}_{0}=\left(\tilde{X}_{t} \tilde{X}_{t}^{\prime}\right)^{-1} \tilde{X}_{t} \tilde{Y}_{t}^{\prime}$. The cross term restriction, $\left(\tilde{X}_{t} \tilde{F}_{t}^{\prime}\right)$, is also set to zero because, in constructing our prior, we are considering the case in which factors don't have any influence on the set of endogenous variables in our DSGE model. We spell out all these details in Appendix C. As far as the prior distribution for the structural parameters is concerned, we maintain the same independence assumption as we did in Section 3; we also consider the same shape and parameterization.

\subsubsection{Posterior distribution}

Given our description of the prior distribution and the likelihood function we can proceed with the illustration of the computation of the posterior distribution.

\footnotetext{
${ }^{16} \mathrm{As}$ in the DSGE-VAR, their population counterparts are used
} 
A new feature of the analysis at this stage has to do with the contribution of the factors in shaping inference. The DSGE model itself does not directly depend on factors, but its estimates account for the larger information set as it appears from the following decomposition

$$
P\left(\Phi, \Sigma_{e}, \theta \mid Y, F\right)=P_{\Phi}\left(\Phi, \Sigma_{e} \mid \theta, Y, F\right) \times P_{\theta}(\theta \mid Y, F)
$$

where the posterior for $\theta, P_{\theta}(\theta \mid Y, F)$, makes clear the dependence on the factors. 